\title{
The multi-layered nature of small-group learning: Productive interactions in object-oriented collaboration
}

\author{
Crina I. Damşa
}

Received: 18 April 2013 / Accepted: 16 April 2014 / Published online: 25 July 2014

(C) The Author(s) 2014. This article is published with open access at Springerlink.com

\begin{abstract}
This article presents a study of small-group interaction in the context of collaborative learning in undergraduate education. The student groups participated in collaborative projects, which involved setting-up, conducting, and reporting on empirical research studies. This study sheds light on the nature of productive interactions, the joint efforts to co-construct knowledge and the shared epistemic agency expected to emerge when groups are addressing ill-structured, complex problems in a collaboration over time. In-depth qualitative analysis and descriptive statistics were used to analyze and interpret interaction data and developing knowledge objects (i.e., research reports) collected during a 20 -week project period. The findings show that productive interactions can take different forms, with discourse-based and object-oriented being the most relevant patterns arising. In the latter case, the emergent knowledge objects also influence the course and productivity of the interaction. Finally, groups manifesting shared epistemic agency produce knowledge objects more complex and suitable to the problems addressed. These findings contribute to a better understanding of the collaborative learning process that includes work on knowledge objects over time. The implications for the educational practice and further research point towards the need for a better understanding of the way groups function when challenged to address complex problems and to participate in knowledge production, how these processes can benefit learning, and what is needed in terms of pedagogical and technological support, to enable students to be more than mere coursetakers, but also producers of knowledge.
\end{abstract}

Keywords Knowledge co-construction $\cdot$ Knowledge objects $\cdot$ Learning in higher education · Productive interaction $\cdot$ Shared epistemic agency $\cdot$ Small-group collaboration

In the context of emerging changes in the knowledge-based society, students in higher education are expected to be able to address ill-structured and open-ended problems, conceive new ideas, show inquiring attitudes and proactive behavior, and capitalize on collective expertise (Goodyear and Zenios 2007). Learning in small groups that focuses on solving open-ended problems and on managing the collaborative process has been proposed as a way

C. I. Damșa $(\bowtie)$

Department of Education, Faculty of Educational Sciences, University of Oslo, PO Box 1092, 0317

Blindern, Oslo, Norway

e-mail: crina.damsa@iped.uio.no 
to expose and enculture students to complex learning situations that stimulate engagement in collaborative knowledge production.

However, conceptualizations of collaborative learning (e.g., Stahl 2009a; Hmelo-Silver et al. 2013) and empirical studies (e.g., Baker 1999; Barron 2003; Hmelo-Silver 2004; Mercer 2002) that have unfolded over the years have not addressed the details of learning in interaction that leads to knowledge production and challenges students to engage in sustained collaborative efforts. While some research studies on collaboration have provided substantial insight into whether and when interaction proves more effective than working alone (e.g., Furberg et al. 2008; Janssen et al. 2010), others have emphasized the role of different variables in mediated interaction (cf. Cress et al. 2013; Slof et al. 2013) or focused on the procedural characteristics of the process, such as social aspects, conflict, or planning (Barron 2003; Engle and Conant 2002; Remesal and Colomina 2013). Fewer studies have explicitly addressed the unfolding (in time and space) relationship between the participants' ongoing interaction (Krange 2007; Sarmiento-Klapper 2009) and the emergence of the knowledge involved.

The rationale underlying this empirical investigation can be found in sociocultural perspectives of learning and development, viewed as a process of co-construction of knowledge that arises from interaction (Valsiner 1994). This is a process that unfolds in time and it is shaped by individuals' knowledge, active engagement, and the intersubjectivity created during interaction. Accordingly, it is by social interaction that individuals align their existing ideas to create new meaning and understanding (Ludvigsen 2010) and through interaction between participants and resources that knowledge comes into use and is materialized into knowledge objects (Paavola and Hakkarainen 2005). From this perspective, knowledge emerges as an interactional accomplishment based on a joint construction process and materialized into shared knowledge objects - "frozen" knowledge. In this context, it appears crucial to gain a deeper understanding of the learning process organized as collaboration around shared knowledge objects, which requires active engagement and participation in this interactional setting and in the joint construction of knowledge. Research needs to address the complex dynamics of this process, which involves acknowledging the connection between these different layers, i.e., interaction, emerging knowledge (objects), students active participation, and their combined dynamics.

The aim of the study is to shed light on the productive interactions thought to occur when university students collaborate in small groups to learn to set up, conduct and report on research. In particular, it examines interactions that are productive during long-term collaborative research projects, with a focus on: how these interactions unfold, whether the interaction proves productive in relation to the emerging knowledge objects (in this case, research reports of collaborative research studies), and learners' active participation - agency — in this collaborative work. Ultimately, the aim is to gain an understanding of the interconnection between the aspects involved in the object-oriented collaborative process and how this can shape and contribute to the learning process.

To this end, the study builds on the conceptualization of learning as a collaborative process of knowledge co-construction. It carries out an in-depth and detailed analysis of higher education students' collaborative group activities, and partly of their products. The following research questions will guide this investigation:

1. What are the characteristics of productive interactions in the context of group objectoriented collaboration?

2. How are productive interactions and knowledge object development interconnected?

3. How is shared epistemic agency expressed and related to the groups' object-oriented collaboration? 
The article begins with an examination of theoretical and empirical studies related to the notion of productive interactions and knowledge objects. Next, it constructs a framework that sets the theoretical basis for understanding the concepts addressed herein and for conducting the empirical analyses. An analysis of empirical material collected from student groups follows. The article concludes with a summary and a discussion of findings, focusing on the interconnection between the aspects under investigation.

\section{Theoretical and empirical perspectives}

\section{Learning as a process of co-construction of knowledge}

The main point of departure for the conceptualizations included in this study involves the sociocultural approach to learning (Vygotsky 1978; Wertsch 1998) and sociogenetic ideas (Valsiner 1994; Valsiner and Van der Veer 2000). Generally, sociocultural approaches emphasize the interdependence of social and individual processes in the co-construction of knowledge. This view of learning and development rests on a number of premises directly relevant to the current conceptualization. One core premise holds that we achieve understanding and knowledge through (social) interaction. Knowledge is constructed as part of the interdependency that involves people interacting with peers, tools, or objects from their environment, primarily through communicative actions (Linell 2009) and in the context of a process that spans time and space (Stahl 2009a; Valsiner and Van der Veer 2000). This view purports that learning and development are rooted in social practices; the process is supposed to start in the intersubjective, external setting. The internalization of ideas, meanings, and knowledge begins as an aspect of collaborative interaction, and it successively transforms into a phenomenon of its own. For this first stage to happen, language or other mediating means are needed to "freeze" the meaning of an internalized event. This results in a process that triggers development or results in (cognitive) artifacts, which are an "internalized form of culturally developed artifacts" (Stahl 2003, p. 7). One aspect that the classic sociocultural writings seem to have dealt with in a less clear fashion is that of externalization. Through externalization, the results of the internal transformations of the social input (into thought, cognitive artifacts, etc.) are communicated to others, who then receive and transform such messages in their personal ways. It places the internalized structures back into the interpersonal space, through a bidirectional process. Accordingly, the individual is in an active process of relating to the environment (physical, social, and cultural), and the construction of knowledge is an outcome of that process (Valsiner and Van der Veer 2000). In this context, knowledge becomes both an outcome and a mediating element in the interactional process. This stance relates directly to another sociocultural premise, which poses that human action is mediated. Hence, interaction and communicative action imply the use of tools, artifacts or objects as mediational means that embody knowledge and experiences accumulated over time. Wertsch (1991) indicated how individuals use and act upon meditational means as being fundamental for understanding, knowledge construction, and learning. These means can also take different roles: in production, artifacts and objects can be outcomes of interaction; when used in the context of interaction, they can function as tools. Furthermore, another particular feature of these mediational means is their nature: not only physical artifacts but also especially those of an intellectual nature (Säljö 2004), such as language, concepts, and structures for reasoning, have mediational value. Wertsch (1991) insisted on the dynamic character of this process, strongly determined by the intersubjective nature of the process, by how this process is mediated by various means - especially by language and by the active participation of the individuals 
involved in this process. Knowledge emerges as an interactional accomplishment based on a combination of the individual contributions, collective processing and actions, and mediational resources involved.

\section{Productive interactions}

Theoretical and empirical studies of interaction (e.g., Baker 1999; Engle and Conant 2002; Furberg et al. 2008; Mercer and Wegerif 1999) have conceptualized productive aspects of interaction in slightly different ways, depending on the theoretical assumptions they build upon. A number of contributions addressing, either explicitly or implicitly, the concept of productive interaction are discussed below.

The sociocultural approach has developed a rather advanced conceptualization of the notion of interaction and how it could be productive, but empirical studies based on these ideas are emerging currently. Theoretically, the sociocultural approach postulates that humans exist and develop in intellectual interdependence and social interaction and that they co-construct their knowledge through this interaction (Valsiner and Van der Veer 2000). This viewpoint involves the belief that (social) interaction is a prerequisite for how knowledge is constructed and used. This interaction, situated in a historical, physical, cultural context, commonly takes place on a regular basis at a micro-social level (Valsiner 1994). The sociocultural approach claims that knowledge is embedded in interaction and, moreover, that the individual processes and structures can be traced to their interaction with others. Productive interactions are mostly described at the microgenetic level of knowledge construction as part of the more general social interaction processes, and are connected to the moment-to-moment (social) interaction among individuals (Ludvigsen 2010).

Empirically, few studies have addressed productivity in interaction from this perspective, and mainly emphasized the dialogical aspects of the interaction rather than how the knowledge emerging from the interaction is being materialized; however, connections with the outcomes of the dialogical interaction have been made at the level of the interpretation. Mercer (2002) and Mercer and Wegerif (1999) elaborated on the concept of exploratory talk, referring to a communicative process for reasoning through talk. Accordingly, such talk occurs when "partners engage critically but constructively with each other's ideas. Relevant information is offered for joint consideration. [...] Agreement is sought as a basis for joint progress. Knowledge is made publicly accountable and reasoning is visible in the talk" (Mercer 2002, p. 16). Furthermore, it recognizes peers' rights to participate and contribute toward the shared goal, activity, or outcome. The term "interthinking" (Mercer 2000) encompasses this notion of people using the language for social and cognitive purposes, such as developing ideas together.

The notion of constructive interaction has been used to conceptualize, within social-cognitive views, the type of interaction with peers that supports learners' better understanding of concepts. This tradition builds on a richer set of empirical studies that contribute to both a better understanding of how interactions can be productive (even if that is not explicitly stated as the core of this conceptualization) at the verbal level and to delineating ways to analyze collaborative encounters. Miyake (1986) developed the notion of constructive interaction as an element of the pedagogical design that encourages learners to talk to each other while attempting to understand specific phenomena and methods of research, but the study did not examine the characteristics of this process. Later studies approached the idea of constructive interaction as an aspect of conversational interaction. Roschelle (1992) and Teasley and Roschelle (1993), in their studies of joint problem space, considered conversational interaction constructive when it enabled students to construct increasingly sophisticated approximations of scientific concepts through the gradual refinement of ambiguous, figurative, and partial meanings. 
In studying collaborative argumentation, Baker (1999) developed an account of constructive interactions and identified two aspects that can be viewed as productive (or constructive). The first involves the productive transformations that lead to the co-construction of meaning, understanding, solutions, or knowledge. More specifically, in these interactions, "new meanings or knowledge are co-elaborated, and/or fulfill some specific (constructive) function with respect to cooperative activity" (Baker 1999, p. 179). Baker emphasized the communicative aspects and how interaction leads to knowledge or understanding through the addition of new knowledge or understanding to eliminate confusion. The second aspect refers to interaction being constructive to the extent that it contributes to a shared goal or cooperative activity through actions that go beyond individual contributions and serve a common purpose. Baker's analyses illustrated argumentative interactions, including the understanding of knowledge, the co-elaboration of meaning, or the filtering of flawed hypotheses. His findings showed that interactive pressure does not lead group peers to resolve verbal conflicts but to draw on different types of knowledge, to determine and differentiate concepts, to negotiate meaning, and to combine elements of solutions.

Attempting to increase the understanding of micro-interactional processes in collective achievements, Barron (2003) emphasized the importance of productive collaboration beyond the accomplishment aspect and the characteristics of interactions that lead to differentially productive joint efforts. She identified aspects influencing the productivity of interaction at the relational and metacognitive levels. Groups considered more productive coordinated and monitored individual contributions to joint work and dealt with issues of power, role status, and engagement. Rather than using cognitive aspects to depict productivity, Barron used the social-relational dimension as a reference point for the analyses (see also Damşa et al. 2013).

Investigating productive disciplinary engagement during collaborative learning projects, Engle and Conant (2002) and Engle and Faux (2006) attempted to characterize the productivity of student engagement in interaction. Accordingly, students become engaged when they make significant contributions to a topic and when their contributions are coordinated among each other. Productive engagement occurs when progress takes place in students' knowledge, materialized in the use of more advanced arguments or more elaborate questions.

Of the different concepts examined here, that of productive interactions brings together ideas of interaction as a mechanism for knowledge construction. Although varying in approach and basic assumptions, the studies discussed above have contributed, too, to a conceptualization of the notion. Thus, productive interaction refers to knowledge co-construction within the context of a knowledge domain, entailing both (joint) actions directed toward shared goals, increased shared understanding of concepts, but also actions that contribute de facto to the construction and progress of the (shared) knowledge objects. Due to this latter feature, productive interactions can be viewed as different from dialogical interactions because they go beyond the level of shared accomplishment at a dialogical level (i.e., problem identification, shared understanding of knowledge, joint plans of action). It reflects one aspect of the knowledge co-construction that had been less explored, and which has the potential to shed light on the innermost mechanisms of the process and how that entails learning.

\section{Knowledge objects}

The investigation of dialogical aspects of the interaction has been mainly the focus of studies on collaboration and collaborative learning. In recent years, various studies (see also Nicolini et al. 2012; Stahl 2009a) pose that it is increasingly important to take into account the knowledge emerging from this interaction. The notion of knowledge object emerges as instrumental here, to depict this aspect of the knowledge that is co-constructed and materialized. 
Attempts to define, more generally, the concept of object did not lead to clear-cut, unambiguous, and indisputable definitions. The sociocultural perspective views the object as an anchor for an activity (Engeström and Sannino 2010; Leont'ev 1978), emphasizes that collective action is inherently object-oriented and that the pursuit of some type of object motivates collaborative work (Kaptelinin 2005). The object defines the activity and becomes the "sense-maker" (Kaptelinin 2005, p. 12), which gives meaning to this activity and the values involved in the activity. What this perspective underscores is that, because of their collective origins, objects are, by definition, partially shared, emerging, and sometimes fragmented. Sociotechnical perspectives and interactionist sociology have focused on the role that various objects (technologies, artifacts) play in organizing work in general and collaboration in particular. From this perspective, objects have a binding role between individuals, groups, and communities (Nicolini et al. 2012), facilitating cross-disciplinary collaboration. Some studies (cf. Engeström \& Sannino 2010) have been concerned with the dual nature of the object. The object has, thus, both projective and objective value, meaning that it represents both the goal to be pursued and the material outcome to be achieved through the activity. Carlile (2002) referred to their role as boundary objects that individuals from different domains can work with, i.e., create, measure, and manipulate.

In this context, the notion of knowledge (or epistemic) object is of main interest. The notion of an epistemic object has been defined primarily within the context of knowledge work in scientific communities (Knorr-Cetina 1997, 2001). It builds on Rheinberger's (1997) conception that the capacity of objects to support collaboration derives from them being experienced as epistemic things; objects become epistemic when they embody what one does not know yet. These are "material entities or processes [...] that constitute the objects of inquiry" (Rheinberger 1997, p. 28). In line with this, Knorr-Cetina (2001) emphasized the difference between objects as instruments, which are objects that are ready to use, a means to an end, and always available, and knowledge objects, which are problematic and open to transformation and further exploration.

Traditionally, a distinction has been made between objects and artifacts, with objects referring to the objective of activity and artifacts to the tools that mediate the achievement of these objectives (Ramduny-Ellis et al. 2005). In learning science research, the notions of object and artifact have been used interchangeably. It was the concept of (knowledge or cognitive) artifacts that received attention. Bereiter's (2002) elaboration on the notion of conceptual artifacts refer to how knowledge work in general takes place, how knowledge is produced, and the idea of knowledge building - as a form of knowledge production and learning in collaboration (Bereiter 2002). With regard to the nature of these artifacts, Bereiter considered that they belong to a realm that encompasses entities such as problems, theories, ideas, concepts, conjectures, interpretations, proofs, criticisms, and the like. From his perspective, an idea, concept, or theory is real (Bereiter 2002). Paavola and Hakkarainen (2005), in their elaboration of learning through knowledge creation approach, emphasized Bereiter's statement that human work focuses increasingly on knowledge objects rather than physical things, which characterizes knowledge work. Furthermore, Bereiter also considered that artifacts play a seminal role in the advancement of knowledge, in which they have multiple values: they are instrumental (i.e., they are used to create other artifacts), they are historical (e.g., they embody knowledge created in time), and they can be the outcome of knowledge work (e.g., they can be shared, articulated, and extended by shared efforts and by mobilizing collective cognitive resources). In his analysis of the mechanisms of small-group interaction during collaborative problem solving, Stahl (2009b) related his conceptualization of the knowledge objects (or cognitive artifacts) to the processes of internalization and externalization discussed in the previous paragraph. Accordingly, he viewed objects and 
artifacts as carriers of (co-constructed) meaning that emerges through consistent use in interaction by individuals engaged in activity together. This meaning "emerges in external, observable, intersubjective world of other people and physical objects" (Stahl 2003, p. 6). Through repeated iterations of the processes described, an object/artifact emerges and combines meaning and knowledge with physical existence.

Within the knowledge building framework, some empirical studies have examined the role of conceptual artifacts in the process. Most relevant are those of Van Aalst and Chan (2007) and Lee et al. (2006)), who investigated how digital portfolios scaffold the collaborative inquiry of high school students using the Knowledge Forum technology. The findings point to the formative value of the portfolios, which represented not only knowledge products but also the materialization of students' developing ideas and a form of scaffolding that helped students recognize and make sense of productive discourse. However, the collaborative aspects of knowledge building were again represented only by the analysis of peer discourse and not by active involvement in creating it. In the research on small group learning, a number of studies dealt with the notion of proposal in virtual math teams (the VMT project) and how that influences or contributes to group work (Stahl 2009c). Proposals can lead to group actions aimed at the clarification of deictic (linguistic) references and then to the discussion of a topic that eventually becomes shared by the entire group. Stahl (2009c) maintained that proposals contribute to a group's object orientation, with mathematical objects being the topics that are negotiated and co-constructed throughout the temporality of the discourse based on different individual contributions. Mathematical objects, ranging from a mathematical sign (Medina et al. 2009) to an idea generated through a proposal (Fuks and Pimentel 2009) to a visualization created by technological means (Çakir et al. 2009; Charles and Shumar 2009), were viewed as more tangible than problems, which are created, maintained, and transmitted through discourse.

While these studies disclose rather advanced conceptualizations of the notion of knowledge objects, at an empirical level there has been no extensive documentation and analysis of smallgroup learning that revealed in detail how knowledge objects are constructed and how they emerge from the interaction. In the context of learning activities that aim to challenge students to go beyond being mere course takers, it is important to have an insight into what is known of how students work together to construct and develop knowledge products. As the studies analyzed above showed, there are insights into the roles objects can fulfill in collaboration (tool/instrument, end product, object of inquiry), but there is little known about the process that takes place when objects are being constructed during the interaction.

\section{Shared epistemic agency}

Efforts directed at jointly co-constructing knowledge require active participation and a combination of individual and collective contributions. Active participation in interaction allows students to go beyond individual efforts (Scardamalia 2002), to become engaged in knowledge construction at the collective level (Charles and Shumar 2009), and to contribute to the shared goals. The assumption that the current study elaborates upon is that agency in collaborative contexts involves a social element that is enhanced during group work. From a sociological viewpoint, Emirbayer and Mische (1998) considered agency to be characterized by experience-based social participation, involving acts of negotiation on the course of future actions. The notion of sharedness in agency presupposes intersubjectivity (Matusov 2001) and interaction between participants; it emphasizes the potential of people to concretize choices made for a particular trajectory of action, not expressed in each individual member's activities or pursuits but in shared efforts at the group level. 
Furthemore, central to agency in knowledge work is the productional aspect. Schwartz and Okita (2004) viewed agency as a system of production and people acting to witness their ideas embodied in concrete products. Their notion of productive agency implies that people produce ideas, artifacts, and objects as part of their agentic patterns, designating the epistemicproductional (Damșa et al. 2010) character of collaborative activities. Accordingly, epistemic agency does not reside within the individual's mind but rather emerges through participation in collective activities. Palonen and Hakkarainen (2000) added that epistemic agency is the concept that reveals students' understanding of the fact that it is not only the teacher who initiates inquiry or activities of knowledge construction but also the students who can initiate, conduct, and steer this process.

This stance places the focus on the joint action and the effects on the objects, resources and those who engage in it. In a joint action, a wider range of concepts or resources is likely to be deployed on the (shared) object than would be the case for individual action.

\section{An integrative analytic framework}

The theoretical perspectives and empirical insights presented above sketch the complexity of the phenomenon under investigation, which leads, consequently, to a challenge when devising an analytic framework to depict this complexity. When addressing this challenge, some particular aspects appear of importance. Namely, a) it is essential to define, even in a preliminary manner, the nature of productive interactions, i.e., how they are different from other types of interaction and how they lead to knowledge construction; b) the temporality involved in the interaction; and c) the multiple (analytic) layers that comprise this process, e.g., interactions, knowledge objects, agency, and their interconnection. Being able to identify and illustrate each of these layers is just one aspect of this analytic challenge. Understanding how these factors are interwoven and how they are part of the learning process is another.

The review of studies on interaction showed various instances of how meaning can emerge through dialog, shared discourse, and conversational encounters. Examples of such frameworks and analytic schemas emphasized the reasoning process in social interaction processes (Sawyer and Berson 2004; Sfard and Kieran 2001), (collaborative) argumentation and meaning making (Baker 1999; Weinberger and Fischer 2006), procedural and relational aspects of interaction (Barron 2003; Rummel and Spada 2005), or deictic aspects of conversation (Lindwall and Lymer 2011). Productive interactions, inter alia, not only comprise these constructive, discursive, and procedural aspects but also refer to something outside this conversational space. They entail the actual production of something-knowledge objects, for example - that embodies the understanding, meaning, or knowledge that has been constructed. Analytically, this involves sequences of collaborative actions moving from one state of the object under construction toward another in a direction that leads to the advancement of these objects. Each case and context defines the "productivity" of interactions in epistemic terms rather than some universal criteria and is expressed in terms of long-term participation and learning, beyond the interaction moment itself. An analytic approach that unifies these layers builds on the discourse-analysis tradition but attempts to go beyond it by adding an analysis of the products of the interaction.

It is in this context that the temporality becomes important. A temporal perspective is needed when attempting to elucidate the way the interaction unfolds and whether it is productive (Ludvigsen 2010). The concept of interaction trajectories encompasses the idea of interaction unfolding in time. Sarmiento-Klapper (2009) states that in longitudinal interactions, temporal and sequential resources are central to constituting activity as continuous. Krange (2007) 
emphasizes that a trajectory perspective creates possibilities for determining how these momentary interaction elements build into continuity, how the interaction process evolves over time, and how participants capitalize on, first, each others' contribution to the joint effort and, second, on the various resources available. For the current study, the notion of temporality creates the framework for explaining the co-construction process from a more dynamic view that captures progress within the given time boundaries. The productive interaction and the related co-construction of knowledge objects are depicted as moment-to-moment events. The interactional moves can be identified as coherent and sequentially organized actions, displayed analytically as collections of episodes.

Finally, the multi-layerdness is expressed through different aspects and holds a great analytic potential. One aspect is represented by the locus of learning, which can be at the individual, the group, or the community level, and expressed in analytic terms by the unit of analysis. This study follows conceptualization by Valsiner \& van der Veer (2000), Ludvigsen and Mørch (2010) or Säljö (2004) acknowledging that meaning making and knowledge are constructed in a less-well-charted middle ground of the interaction, involving individual and collective input. Social interaction at the group level, expressed in language and actions, allows us to pin down the important aspects of the knowledge construction effort. The unit of analysis is not the individual or the group but the joint action (verbal or otherwise) directed at the coconstruction and elaboration of the knowledge objects involved - in other words, the mediated interaction (Stahl 2013). This mediation leads us to the second aspect of the process being multi-layered, which comprises the elements depicted in the previous sections. It is the combination of the interaction (productive, as envisioned here), the objects that mediate this interaction (with different functions), and the agency of the group as a construct of individual engagement and collective commission. The way these are woven together is also related to the temporality of the whole process and to how these components combine while unfolding in time.

Concretely, to construct analysis instruments, this framework envisions these concepts (or layers) as follows. In addition to the productive interactions, which are defined at the start of this section, knowledge objects are conceived as an externalization of knowledge, "freezing" knowledge at certain moments in time. The objects embody knowledge that is not in the mind but rather is externalized in something (such as ideas or actions) that is accessible to the whole group and can be used to produce new knowledge. As an analytic stance, this study adopts the distinction between generalized objects of activity, which are historically developed, and situational objects (Jahreie 2010), which are discursively constructed in the interaction of the learners. This position situates the shared knowledge objects at the center of the interaction process, either as instruments or as objects of inquiry, not only as end outcomes. It views the knowledge objects as rather open-ended projections oriented toward something that is not known for sure and, as a consequence, as generators of new conceptions and solutions (Miettinen and Virkkunen 2005). As a result, work with these objects is a continuous process of transforming an object from its current state into a required end state. Finally, it regards the construct of shared epistemic agency as the capacity to enable a deliberate, joint, object-oriented interaction. This type of agency expresses different qualities of the knowledge co-construction process. The epistemic aspect refers to the active involvement of the group with knowledge and its materialization into knowledge objects. The aspect of sharedness implies that agency is not the expression of each individual member's activities or pursuits but is, rather, the expression of joint efforts at the group level. Furthermore, shared epistemic agency is seen as an emerging, recursive capacity that manifests itself and unfolds during the interaction. 


\section{Methods}

\section{Research context}

This article reports on a design-based research project (Collins et al. 2004) concerning learning in higher education. The project involved studying collaborative learning settings using a codesign approach. The initial iteration consisted of investigating collaborative groups in existing settings; the iteration presented in this article provided input for re-designing the collaborative activities and technology features. This iteration, which spanned the whole course period, employed the model of distributed project work (see Ahuja and Galvin 2003) and was organized within the Bachelor Thesis, a 20-week course offered in the third and final year of bachelor degree study in educational sciences. The course aims to support students in integrating and applying previously acquired scientific research knowledge and in reporting on the research studies conducted during the course period. The course curriculum was redesigned with an emphasis on open-ended tasks and the co-construction of shared knowledge objects (Paavola and Hakkarainen 2005). During an introductory workshop, the participants were introduced to concepts such as small-group learning projects, open-ended and illstructured problems, object-oriented collaboration, and online technology, and they met two external clients invited to participate in the project.

\section{Participants}

Fourteen out of the 120 undergraduate students enrolled in the Bachelor Thesis course at a large Dutch university participated in this study. Direct access to the sample group was gained through a call to students and their teachers, with the participating students deciding to participate voluntarily - a mixed purposeful sampling approach, including typical case sampling (Creswell, 2007). Seven full-time and seven part-time educational science students (two men and 12 women; average age $=30.1, \mathrm{SD}=9.9$ ) participated, organized into five groups. All participants were in the final year of the undergraduate program. The two participating clients were recruited from a pool maintained by the supervising teacher, of external companies and organizations interested in involving and supporting students in their activities, through either internship or research projects. Both clients involved were private consultancy organizations in the field of educational innovation. Client 1 specialized in instructional design using online technology (e.g., games or mobile learning modules). Client 2 specialized in knowledge management and educational innovation services using Virtual Learning Community (VLC), an online environment for educational activities.

Design iterations and pedagogical scenarios

The design unit was the pedagogical scenario - a purposeful description of instructional and learning activities taking place in a certain context. The course coordinated by the participating teacher was re-designed following a set of design principles (see Sins et al. 2008), as follows:

- Collaborative projects involving social interaction replaced individual assignments and projects;

- Open-ended and complex problems were introduced, requiring inquiry and active engagement with knowledge;

- Shared knowledge objects were requested as part of the solutions envisioned for the problems; 
- Technology mediation, an online application that supports collaboration, replaced a course management system; and

- Interactive mentoring and supervision sessions on an as-needed basis and were introduced, instead of lectures.

The participating teacher was involved in the re-design of the learning activities. Student learning was enhanced by facilitating participation in object-oriented collaborative research projects. The student groups were provided scaffolding for organizing their research activities. They were encouraged to organize and manage their own projects by using skills accumulated in prior research courses. During the project period, face-to-face sessions with the teacher were organized on an as-needed basis. Participants presented the final group product, a common research report, on a Bachelor Thesis congress day. The research project consisted of four phases: project initiation, research preparation, construction, and delivery. These phases, the corresponding activities, and the knowledge objects are presented in Table 1.

Collaborative research projects

The task, to collaboratively set up, conduct, and report on a research project, was presented to and discussed with all participants. Groups were formed at the beginning of the course period based on the students' interest in the research topics proposed by external clients. In the introductory workshop, the two clients presented a number of problem situations that they wanted examined. In the period that followed, students had a chance to discuss their preferences and form groups based on their interest in specific topics, chosen from the ones proposed by the clients. Once groups were formed, they were encouraged to talk with the clients to give the initially presented research problem a clearer shape. The teacher facilitated this dialog. Client 1 required research on the design and implementation of educational games in secondary professional education. Two student groups worked on this project. Client 2 requested an investigation of learner behavior in this environment. Three student groups chose to investigate different aspects of this topic. When the research topics were specified together with the clients and approved by the teacher, the groups could proceed with their research study.

Table 1 Overview of research phases

\begin{tabular}{|c|c|c|c|}
\hline Research phase & Activities & Intermediate objects & $\begin{array}{l}\text { Final knowledge } \\
\text { object }\end{array}$ \\
\hline $\begin{array}{l}\text { Project initiation } \\
\text { phase }\end{array}$ & $\begin{array}{l}\text { Finding a client and negotiating } \\
\text { a research project } \\
\text { Preparing a project plan }\end{array}$ & Project plan & $\begin{array}{l}\text { Research article } \\
\text { Presentation slides }\end{array}$ \\
\hline $\begin{array}{l}\text { Research preparation } \\
\text { phase }\end{array}$ & $\begin{array}{l}\text { Describing the research problem } \\
\text { Formulating research questions } \\
\text { Creating a theoretical framework } \\
\text { Identifying and describing research } \\
\text { methods } \\
\text { Searching for respondents }\end{array}$ & Research plan & \\
\hline Construction phase & $\begin{array}{l}\text { Constructing instruments (for } \\
\text { collecting and analyzing data) } \\
\text { Collecting data } \\
\text { Analyzing data } \\
\text { Interpreting results }\end{array}$ & $\begin{array}{l}\text { Data-collection \& data analysis } \\
\text { instruments } \\
\text { Drafts reports of findings }\end{array}$ & \\
\hline Delivery & $\begin{array}{l}\text { Reporting on project and results } \\
\text { Presenting the project and results }\end{array}$ & $\begin{array}{l}\text { Article drafts } \\
\text { Presentation slides }\end{array}$ & \\
\hline
\end{tabular}


Technology support

The technological support for collaboration was provided through the online course management system Blackboard ${ }^{\circledR}$. The system provided support for both managing the course and making course documents available, as well as for within-group collaboration. Course objectives and guidelines were posted by the teacher in the virtual course environment in specific online folders - Course Documents - and announcements were placed in the Announcements space. A Discussion Board was available for posting and discussing matters relevant to all participants in the course. For the collaborative work, separate virtual spaces were created for each group. This space had a File Exchange functionality, which allowed group members to upload, download, and exchange documents, materials, and report versions. A Chat functionality was available for synchronous communication. Groups also had access to regular email. By providing students with space to share their work on the joint documents, the intention was to stimulate and enhance their exchange of ideas, versions of the materials they had worked on, by going beyond the constraints of face-to-face meetings. Students were encouraged to provide feedback, annotate, and elaborate on one another's drafts. Chat was introduced with the explicit intention to stimulate and facilitate discussion of these materials while group members were not located in one another's proximity.

Data collection and analysis

The design-based research approach was used as an overarching methodological framework. Within this, the empirical study was conducted as a set of case studies (Yin 2003). It defines a case as the activities and the products of one group of students during the 20-week course period. A variety of data was collected to achieve triangulation (Yin 2003). The data set consisted of field notes during meetings with clients and the teacher, interaction data (group discussions and e-mails), reflective data (group interviews), group products, and all the report iterations (which varied per group, from a minimum of 11 to a maximum 29 iterations). This contribution involves a cross-section of the data, drawing primarily upon group discussions, group products, interviews, and field notes. The data were chronologically ordered, and the recordings were transcribed verbatim in the original Dutch; excerpts in the article were translated by the author.

The analysis followed the conceptual avenues outlined in the analytic framework section above, which highlight productive interaction, knowledge objects, and shared epistemic agency as essential layers of the learning process conceived as knowledge co-construction. In addition, the actions and objects identified were followed in time, with a focus on how interactions generate new actions, which can consequently influence and affect the developing objects. This trajectory approach has the purpose of documenting and depicting how interaction unfolds and the incremental development of the knowledge objects that emerge from the interaction. Eventually, the analysis attempts to provide substantiation for establishing a connection between how this co-construction process takes place and students' learning.

The analysis focused on three discrete aspects. First, group interaction was examined using a discourse-analysis technique and descriptive statistics to create an overview of the type of verbal actions in the interactional space (see Sarmiento-Klapper 2009; Stahl 2009c). Relevant (or theme-based) episodes of interaction were identified in the data corpus, an episode corresponding to relatively bounded sequences of speech or encounters in the group discussion (Linell 2009). The unit of the analysis was combined: the episodes indicated the general thematic orientation of the discussion, while the coding of the verbal actions (in the context of 
an episode/theme) indicated the individual but contextualized contribution to this collective discourse. A coding scheme developed in a previous study (Damşa et al. 2010), emerging from theory-based categories through iterative analysis of empirical data, was further refined and applied (Annex 1 displays a complete overview of the coding categories). It consists of three dimensions of action: epistemic, regulative, and other, and reflected the types of actions that can be identified in interaction following the theoretical aspects deemed essential in the coconstruction process. The first category is that of epistemic actions - comprising actions that involved knowledge and dealing with knowledge-related aspects (ideas, concepts, etc.); the second that of regulative actions, which involves actions aimed at organizing the interaction, such as planning, coordinating, monitoring, and reflecting on the collaborative process. The remaining episodes were coded as other types of actions. These categories of actions are considered to reflect the gradual involvement of the group with knowledge, starting with identification of the problem, continuing with the brainstorming of ideas, then with the elaboration into object drafts, etc. An inter-rater reliability test was conducted by the researcher and another, independent person, who both applied the coding scheme to six randomly selected excerpts from two groups' discussion protocols. A sufficient inter-rater agreement between two independent coders was achieved (kappa $=.80$ ).

A second layer comprised a combined analysis of interaction and of the knowledge objects that emerged from and were developed during this interaction. Interaction-analysis techniques (Jordan and Henderson 1995) were used for an in-depth examination of the relevant episodes. Key events (Webster and Mertova 2007)-actions that triggered subsequent actions and led to a particular, relevant development regarding the shared objects (in discussions, emails, or object iterations)-were identified in the (conversational) episodes. Object development was analyzed in conjunction with these key events in the interaction. Object versions were elaborated upon immediately after an identified key event; a timeframe was used for a maximum of 1 week to identify such pairs of key events and object-oriented actions. The analyses of the object versions, inspired by document analysis (Bowen 2009), focused on identifying changes in the object structure, volume, and complexity as a follow-up to the interactional encounters. Figure 1 shows how the analysis unfolded. The circled section represents a sequence of data materials illustrating connections between the interactional elements, followed by actions upon the emerging object iterations.

Finally, the third layer, the groups' shared epistemic agency, was disclosed by qualifying (sequences of) actions identified during the interaction analysis. This took place through a search for regularities in the occurrence of actions that indicated deliberate, strategic, and reflective conduct. The previous two layers (interaction and knowledge objects) were central to the analysis. The identification and analysis of the shared epistemic agency had the purpose of showing how active participation and sustained engagement are important in achieving co-construction and how they can complement the other layers in the process.

In addition, the quality of the groups' final knowledge objects was determined by using a standardized evaluation form based on criteria established by the teachers of the course. This form allowed the grading of the groups' articles with grades ranging from one to ten on the dimensions of content and writing quality. The content dimension consisted of five elements: the synthesis of material from scientific sources, the elaboration of the research problem and questions, the elaboration of the research design and methods, and the indicated scientific and practical value of the research study. The writing quality dimension refers to the structure of the article, language use, punctuation, and the academic writing guidelines. Two independent evaluators graded each article, with a sufficient inter-rater reliability (kappa=.90). 
Episode 1

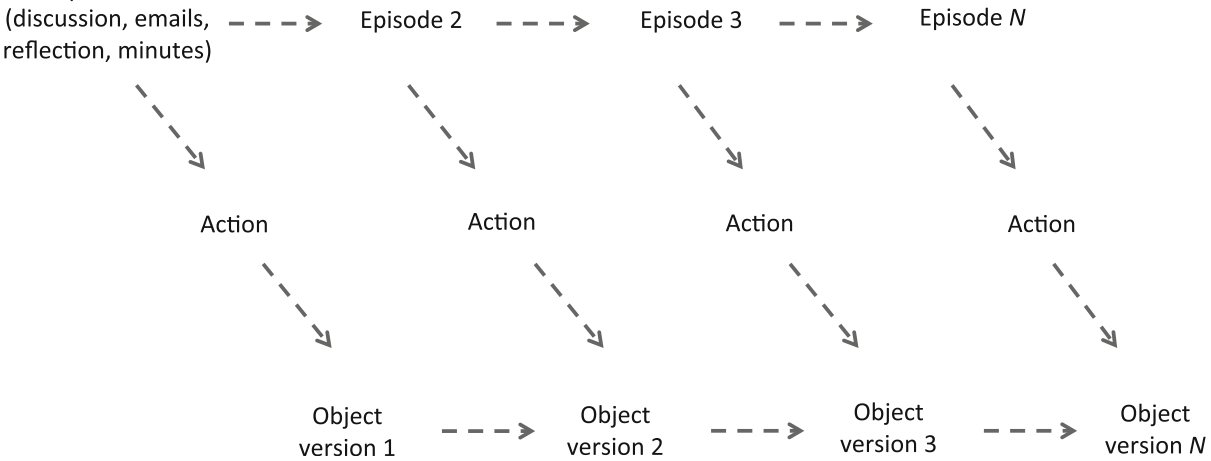

Fig. 1 Analysis model

\section{Results}

This section begins by presenting a general overview of the type of actions identified in the five groups interaction upon the coding of the group discussions. It continues by illustrating interactional episodes that are considered productive and connects these to instances of knowledge objects developed by groups to explain different ways in which this productiveness is expressed in the object development. In addition, results indicating agentic conduct are discussed using a series of data excerpts from one group's interaction. The findings are summarized in a final sub-section.

Overview of interaction types at the group level

The six coding categories of interactive actions provided a first insight into the type of interactions that were predominant in each group's collaborative work (Table 2).

The first notable finding is that, in Groups $\mathrm{A}$ and $\mathrm{C}$ the most frequent actions were those aimed at creating a shared understanding of the problem, ideas, or knowledge. Sharing knowledge and information and regulative actions are the other types of actions that occurred rather often in these groups' interaction. Regulative actions occurred, too, but appear less frequent than in Group B's interaction, in comparison. This overview indicates a greater focus on actions that involve joint (discursive) activity with knowledge. Sharing ideas, information, or knowledge or discussing and negotiating the meaning of concepts and constructing shared understanding of these issues indicates that these groups had a strong epistemic orientation.

Table 2 Frequencies of types of interaction

\begin{tabular}{lllllr}
\hline Category & Group A & Group B & Group C & Group D & Group E \\
\hline 1 Creating awareness & 10 & 8 & 13 & 12 & 13 \\
2 Sharing knowledge & 20 & 14 & 18 & 18 & 15 \\
3 Creating shared understanding & $\mathbf{2 7}$ & 14 & $\mathbf{2 9}$ & 22 & 24 \\
4 Generative collaborative actions & 10 & 12 & 14 & $\mathbf{2 9}$ & $\mathbf{3 1}$ \\
5 Regulative activities & 23 & $\mathbf{3 8}$ & 15 & 12 & 7 \\
6 Other & 10 & 14 & 11 & 7 \\
\hline
\end{tabular}


However, it is noted that discursive interactions, which serve as preparation for knowledge construction, are predominant.

Conversely, Groups D and E appear to have interacted most frequently through actions that led to the generation of ideas and knowledge. Both groups show a relatively high frequency of such actions, followed by actions aimed at creating shared understanding and those aimed at sharing knowledge and information. The rather low frequency of regulative and other types of actions indicate that these groups were more focused on the epistemic aspects of the interaction. This distribution of types of actions indicates that these two groups' activities were discernibly more concerned with working jointly toward generating knowledge, built on discursive interaction aimed at collecting information and creating a shared understanding of the knowledge gathered or emerging in the group. Regulative actions seem to have been performed to the extent needed to ensure that the group functioned efficiently, and priority is given to the productive types of action that contribute to advancing the knowledge objects.

Finally, Group B's conversational interaction was concerned predominantly with regulative aspects of the collaboration. This means that the group often discussed the division of labor, the organization, and the coordination of the collaborative process and monitored the work performed by individual members. We also observe that actions in the category other (social chat, for example) are just as high in frequency as the actions of sharing knowledge and creating shared understanding. The types of action identified as epistemic (creating awareness of problems, sharing knowledge, and generating knowledge) are identified in this groups' interaction but do not seem to have been the focus of their collaborative process. As shown in different episodes of their interaction, this group seemed to organize collaboration in which a division of labor and individual work, accompanied by coordination and monitoring of individual contributions, prevailed.

The quality of the final knowledge objects was assessed by the supervising teacher using the evaluation form. Groups that performed epistemic actions at the generative level more frequently, such as collaborative idea uptake and co-elaborating on ideas and object versions (Groups D and E), produced objects of higher quality - as opposed to the group that frequently employed a division of labor and relied on individual contributions (Group B). Groups A and C, which displayed mainly interactions that led to awareness and shared understanding of knowledge and problems, obtained grades in the middle range, lower than those of Groups D and E.

Productiveness through discursive interaction

This section discusses interactional episodes from Group A's data. This group collaborated with Client 1, who was interested in gaining more insight into the use of gaming in secondary vocational education. The group examined the role and the added value of educational games used as learning tools in three vocational education institutions. They conducted observations of pupils during the use of a computer game and interviews after. They developed the interview protocol and adapted an observation scheme; then, analyzed and reported their findings in a research report, and in a plenary presentation to the teacher, their peers, and the client.

Once identified and labeled, the interaction sequences singled out for this in-depth analysis are linked to actual object development. The first excerpt originated in a discussion during the preparation phase of the research project, when the group members tackled the research question formulation. This group started the project by collecting information on the use of educational games in secondary vocational education. They discussed the information gathered in weekly face-to-face meetings. In the third project week, this group decided to start work on their research plan. 
Excerpt 1. Group A face-to-face discussion (3rd project week) ${ }^{1}$

\begin{tabular}{|c|c|c|}
\hline 1. Fleur: & $\begin{array}{l}\text { "...Is it possible to brainstorm on the research questions } \\
\text { this evening? }\end{array}$ & 1-identifying focus ${ }^{2}$ \\
\hline 2. Eliza: & Yes, it seems a very good idea. & \\
\hline 3. Fleur: & $\begin{array}{l}\text { It's funny, I was reading those articles you sent [...]. That } \\
\text { research is on a game, IT emperor, I actually don't know } \\
\text { what that is. That gave me ideas, we could research } \\
\text { whether motivation for learning increases through } \\
\text { playing a game... }\end{array}$ & $\begin{array}{l}\text { 2-sharing knowledge } \\
\text { 3-explaining ideas }\end{array}$ \\
\hline 4. Fleur: & $\begin{array}{l}\text { Yes, what are the obstacles when playing, that is a } \\
\text { research question. }\end{array}$ & \\
\hline 5. Eliza: & Which factors... & \\
\hline 6. Fleur: & $\begin{array}{l}\text { Wait a second, do we have to formulate a main question } \\
\text { too?... because I didn't really understand that. In the } \\
\text { methodology course the question types were used } \\
\text { wrongly all the time. Everybody calls them research } \\
\text { questions. I've got the idea that we make the same } \\
\text { mistake. Don't we have to clarify this before formulating } \\
\text { the questions for our research? }\end{array}$ & $\begin{array}{l}\text { 1-stating problem } \\
1 \text {-identifying lack of knowledge }\end{array}$ \\
\hline 7. Eliza: & Yes, you are right, this must be clear for the three of us. & \\
\hline 8. Ted: & I agree. $[\ldots]$ & \\
\hline 9. Fleur: & In any case, you have the main question and underneath... & \\
\hline 10. Eliza: & $\begin{array}{l}\text {...you have the research questions. So, main question and } \\
\text { detailed research question. It is actually an itemization. }\end{array}$ & 3-creating explanations \\
\hline 11. Ted: & $\begin{array}{l}\text { And that one you operationalize, in questionnaire questions, } \\
\text { for example. }\end{array}$ & \\
\hline 12. Fleur: & $\begin{array}{l}\text { So, do we need to have a main question as well? Or do we } \\
\text { have one already? }\end{array}$ & 3-re-framing problem \\
\hline 13. Ted: & Of course we need one. & \\
\hline 14. Fleur: & $\begin{array}{l}\text { What could an educative game add to the learning process } \\
\text { and to the motivation. Something in this direction? }\end{array}$ & 4-generating ideas \\
\hline 15. Ted: & Yes, how can ... & \\
\hline 16. Fleur: & $\begin{array}{l}\text {... what can an educative game add to the learning process and } \\
\text { to the motivation of students in vocational education." }\end{array}$ & 4-elaborating ideas \\
\hline
\end{tabular}

The excerpt shows an example of an interaction sequence that illustrates how students attempt to create a shared understanding of concepts and ideas. During the discussion, group members realize that they lack a clear understanding of the research questions and of how to formulate these questions. One member of the group points to the problem-the different understandings or a misunderstanding of the concept research question (line 6). The others

\footnotetext{
${ }^{1}$ Transcription conventions:

[...] : Utterances removed from the original dialog

... utterance: Start of quoted excerpt

utterance... utterance: Short pause in speech

utterance....: End of quoted excerpt. The original group discussion continues

(text) : Non-verbal actions registered in the recording

[text]: Author's comments in the original text

(text in italics): Sections in the excerpts related to coding categories

${ }^{2}$ The figure indicates the number of the coding category, the label the action belonging to that category.
} 
agree that they must clarify the incongruent understanding of the concept (lines 7 and 8) and decide to dedicate part of the discussion to this issue. They attempt to fine-tune their understanding of the concept. One group member provides her own understanding of the concept (line 10); another provides an elaboration (line 11). Another member offers the example of a concrete alternative (line 14), which the group continues to elaborate upon (line 16).

The discussion fragment shows that group members realize the importance of having a shared understanding of the concepts that they must apply before developing the knowledge object itself. In this interaction, the group makes progress on concept understanding through an exchange of insights, ideas, and knowledge sources. Creating a shared understanding of the concepts and giving these concepts concrete meanings in the context of their research helps them to take a step forward and creates premises to begin work on the shared object. This specific interaction instance illustrates this group's approach to object-oriented work, while their interaction, in general, was aimed at creating shared understanding and ideas or knowledge from sources and less at joint idea generation and elaboration.

Excerpt 2 shows two versions of the shared object created by this group at different moments in time, i.e., before and after the group discussion episode presented above. The text in the column headed "Initial understanding and formulation" comes from a version that group members prepared the day before they met. The text in the column headed "Formulation after group discussion" is a section in a version produced by the group after the discussion shown in Excerpt 1.

\section{Excerpt 2. Selection of sequences in object progression}

\begin{tabular}{|c|c|c|}
\hline $\begin{array}{l}\text { Initial understanding and formulation } \\
\text { (2nd project week) } \\
\text { "We can think of research questions like: } \\
\text { a. What is the definition of a game? } \\
\text { On Wikipedia there are simple ones: } \\
\text { 'a computer game, is a game that is } \\
\text { played on a computer'. It can be } \\
\text { played on a computer, Playstation, } \\
\text { PDA, mobile phone, mobile } \\
\text { computer. } \\
\text { b. Is an educational game } \\
\text { an addition to the learning process? In } \\
\text { which the motivation plays an } \\
\text { important role? Reading this now I } \\
\text { realize this is not the right formulation } \\
\text { if we want to investigate statistically. } \\
\text { Should it be a closed question? } \\
\text { Other formulation: } \\
\text { c. Does an educational } \\
\text { game have an effect on the learning } \\
\text { process, and hence, on the motivation } \\
\text { of the students? Should we only talk } \\
\text { about motivation, and that we look at } \\
\text { the learning process through it? } \\
\text { d. When is an educational game } \\
\text { educational? When do people speak } \\
\text { about educational games? Answer this } \\
\text { question with a literature review, } \\
\text { hence not necessary to be a closed } \\
\text { question. } \\
\text { e. How do students feel when playing } \\
\text { games? This one too formulated as }\end{array}$ & $\begin{array}{l}\text { Group } \\
\text { discussion } \\
\text { (see excerpt 1) } \\
\quad \& \\
\text { elaboration } \\
\quad \text { of } \\
\text { material } \\
\text { after } \\
2 \text { weeks }\end{array}$ & $\begin{array}{l}\text { Formulation after group discussion } \\
\text { (4th project week) } \\
\text { Main research question: What do } \\
\text { educative games add to the } \\
\text { learning process and the } \\
\text { motivation of students? } \\
\text { Based on this main research question } \\
\text { we formulated the focus of our } \\
\text { research in sub-questions: } \\
\text { 1. What are the criteria for defining a } \\
\text { game as educational? } \\
\text { 2.How do students experience } \\
\text { educational games in a learning/ } \\
\text { educational context? } \\
\text { 3. Which elements of educational } \\
\text { games motivate learners?" }\end{array}$ \\
\hline
\end{tabular}


open question, answered with

interviews?

f. Which of the elements below do

students appreciate more? Statistical

analysis?

Players and competition

Making decisions, keeping control

Goal aim, begin, end

Learning goal

One can detect rather murky ideas in the first column of this excerpt. Explanations added by the creator of the text (in italics) indicate that these ideas are still in development and that the author feels uncertain about the direction to take. The explanations are very tentative; some questions are formulated, and the group discussion shows that some of the group members consider these suitable research questions for their study. In the selected discussion in Excerpt 1 , it is stated that research questions are not the same as questionnaires or interview questions. It occurs to all the group members that some of the questions in this preliminary document are actually formulated incorrectly. The discussion helps them to understand the difference between the types of questions and to create a shared understanding of how to formulate research questions. The text in the column headed "Formulation after group discussion" resulted from revisions applied in the week after this discussion, and reflects a much better synthesis of the knowledge the group discussed about. This second version shows that the group understood the notion of research question and how that is supposed to express the topic of their empirical study, and not be part of an instrument used to collect data.

The following discussion excerpt follows the elaboration and work on the knowledge object that led to the last version of the research questions, as displayed in Excerpt 2 above.

Excerpt 3. Group A discussion (6th project week)

\footnotetext{
1. Eliza: “...so, we formulated these questions, and I think it summarizes our ideas. Don't you think?

3-re-framing focus

2. Ted: Yeah, I think the part with the games is fine.
3. Fleur: But we didn't include defining the games in it...

3-problematizing

4. Eliza: But it should be part of the answer. We discussed that, that we don $t$ take it up in the questions, didn $\mathrm{t}$ we?

5. Fleur: But the research questions, they show our focus, and isn't that what we are after, games in learning?

3-structuring knowledge

6. Eliza: True! But do we really need to add something on what games are?

7. Fleur: I think we do. You can't just ask about what games add to learning and how they motivate learning without explaining what they are...

8. Ted: But don't we do that through the literature?

9. Fleur: Well... that is possible. But we are not asking in the research questions... shouldn't we? I really think this is not good as it is now.

10. Eliza: Hmmm... I think I am getting your point... but then we need to rephrase.

11. Ted: No, we can use the literature to formulate a definition.

12. Fleur: We need a question first, I think. Which we can answer through the literature. $[\ldots]$

3-re-framing problem
} 
13. Ted: Are you sure?

14. Fleur: Ehm... I think that s how it works. What do you think, El?

15. Eliza: I am not sure. I think we should ask John [supervising teacher]"

In the previous excerpt (Excerpt 2), showing a section of the knowledge object at various stages of development, it can be noted that the group succeeded in synthesizing essential knowledge to formulate their research questions. This leads to progress in their object-oriented work in that the aspects that was rather unclear in the previous version (e.g., what research questions vs. interview questions are, or what is important enough to be incorporated into the research questions). However, in this excerpt, the conversation returns to the matters that have been addressed in previous discussions, such as the definition of a game and whether it should be addressed in the research questions (line 3). The group has a good (and shared) understanding of what they are after in their research (line 7-what games add to learning and how they motivate it), but they seem to stumble over aspects that have not been clarified, even if they were addressed in other discussions. The discussion is concerned with agreeing whether or not to insert this in their questions (lines 6, $7,12,14)$ and the technical aspect of how to actually do this (lines 8, 11). The group seems confused and eventually adjourns discussing this aspect by introducing the alternative of consulting their supervising teacher (lines 13-15).

While the clear depiction of the research questions (in Excerpt 2), as they emerged from previous discussions, indicates the group members' understanding of the research problem and topic, in this final discussion excerpt, they seem unable to capitalize on that progress. They materialize the shared understanding and ideas they have clarified through their face-to-face discussion into a new version of the knowledge object (i.e., research questions), but they return to the same topic in their subsequent face-to-face meeting. While their discursive interaction seems to be productive in the sense that clarification and a shared understanding of ideas are taking place, it appears that it does not always lead to the group materializing it into more advanced versions of the knowledge object.

Productiveness through iterative co-construction

The following episodes illustrate interaction instances in Group D's face-to-face discussions. This group collaborated with Client 2, who requested an examination of the role of feedback in a virtual action learning environment. Using an electronic learning platform, this client implements virtual action learning, which involves learners solving and uploading assignments into the system, and using other learners' directed feedback to revise their products. Group D decided in agreement with the client to investigate the role of peer feedback on the learning of the participants in this environment. They collected log data from this virtual environment, products, and feedback on these products. Their project and findings were reported in a common research report and a plenary presentation at the end of the course period.

The general collaborative strategy of the group was characterized by frequent faceto-face meetings, during which both logistics and content-related issues were discussed. Most of the ideas brought forward during these discussions were provisionally elaborated on the spot and provided with feedback by the others. One group member took notes, while the other two continued the elaboration verbally. When not 
able to meet face-to-face, they wrote down their ideas and emailed them, asking for feedback. At the moment of this discussion, during the preparation phase, the group met to decide and elaborate on the research questions and main concepts to be defined in their research plan. These aspects, already tackled in the project plan, needed elaboration and specificity.

Excerpt 4. Group D face-to-face discussion (5th project week)

\begin{tabular}{|c|c|c|}
\hline 1. Alice: & $\begin{array}{l}\text { "... Shall we try to organize our ideas about feedback, what } \\
\text { we talked about before... some terms and definitions we } \\
\text { need to understand so we know what we want to } \\
\text { investigate... let's get the questions. }\end{array}$ & 1-identifying focus \\
\hline 2. Elly: & $\begin{array}{l}\text {...oh, yes, the project plan, let's get that document with the } \\
\text { questions we already formulated. (Searching for the plan) }\end{array}$ & 4 -idea uptake \\
\hline 3. Elly: & What do we call feedback? & \\
\hline 4. Jane: & $\begin{array}{l}\text { Let's first see..., what is feedback for us, and what is } \\
\text { feedback in the VLC. }\end{array}$ & 3-problematizing \\
\hline 5. Alice: & Shall we just look what we wrote about that in the plan? $[\ldots]$ & \\
\hline 6. Jane: & $\begin{array}{l}\text { So, we can indicate here that feedback can be given in } \\
\text { different ways and that we focus on peer-feedback, } \\
\text { suggestions for improvement and rating from peers. }\end{array}$ & 4-generating ideas \\
\hline 7. Elly: & Yes, then we can elaborate. Let's write that down. (Typing) & \\
\hline 8. Elly: & OK, what is feedback? & \\
\hline 9. Alice: & Feedback is... how is it defined in those sources? & \\
\hline 10. Elly: & $\begin{array}{l}\text { I don't have them, but I remember... linking back the results } \\
\text { of the collaboration. }\end{array}$ & 2-sharing information \\
\hline 11. Jane: & We must first write the definition of feedback. & \\
\hline 12. Elly: & But don't forget we focus on peer-feedback. & 4-re-framing \\
\hline 13. Alice: & But linking back the results of collaboration is too vague... & \\
\hline 14. Jane: & The reaction, $\ldots$ or response then...? & \\
\hline 15: Alice: & $\begin{array}{l}\text { Yes, response, it is response on a..., you could say, product, } \\
\text { from a peer? }\end{array}$ & 4-idea up-take \\
\hline 16. Elly: & ...inside de VLC... & \\
\hline 17. Jane: & $\begin{array}{l}\text { Yes, don't make it too complicated. Suggestions for } \\
\text { improvement for the product in VLC by peers. }\end{array}$ & 4-elaborating ideas \\
\hline 18. Alice: & OK. (Typing) ..." & \\
\hline
\end{tabular}

One group member identifies a focus for the discussion and underlines the importance of a good understanding of the domain, the questions, and the main concepts as a condition for setting up a good research study (line 1). They retrieve the project plan they created in earlier stages as a source of and support for discussion (lines 2 and 5). The interaction sequence continues by structuring the talk on the concept in discussion-feedback (line 3) - and framing this concept (line 4). The group uses ideas from the initial object to elaborate collaboratively on the new object iteration (line 5). One group member points out that the concept needs specification, and the group reframes it (line 12). The ideas generated are written down and then taken up by the other group members (lines 15 and 16). The group starts elaborating on these ideas (line 17).

This excerpt illustrates a different aspect of productive interaction. This group's strategy goes beyond creating a shared understanding of concepts and individual task performance. 
Instead, they attend to generating ideas and negotiating them. Moreover, the entire group then takes up these ideas and elaborates upon them, and the knowledge object gains shape as they document these ideas. This interaction can be labeled productive due to the visible progress of the knowledge object.

To illustrate this progress, Excerpt 5 shows a section of the shared knowledge object created by Group D during the aforementioned discussion and beyond. The comparison between a section of the initial version (the project plan) with the elaborated version in the newly produced object (research plan) illustrates the productive value of this interaction sequence.

Excerpt 5. Fragment of content of shared knowledge object iterations

\begin{tabular}{|c|c|c|}
\hline Initial object content & Group & Co-elaborated object (6th project week) \\
\hline (4th project week) & discussion & ...Necessary definition: \\
\hline "Research questions: & $\begin{array}{l}\text { (see } \\
\text { excernt 4) }\end{array}$ & $\begin{array}{l}\text {-How is feedback defined in the context of the virtual } \\
\text { learning community? }\end{array}$ \\
\hline Possible sub-questions & & Definition: giving and receiving suggestions for \\
\hline -What is feedback? & & improvement on the products or artifacts to \\
\hline $\begin{array}{l}\text {-Which influence does feedback } \\
\text { have on the learning process? }\end{array}$ & & $\begin{array}{l}\text { and from course-peers. } \\
\text { (Definition of peer-feedback needs to be looked }\end{array}$ \\
\hline -Does the way feedback is & & up in the literature and will be processed here.) \\
\hline $\begin{array}{l}\text { given have an influence on the } \\
\text { learning process? }\end{array}$ & & $\begin{array}{l}\text { Research questions and ideas for investigation: } \\
\text { In which way is peer-feedback given inside a VLC? }\end{array}$ \\
\hline $\begin{array}{l}\text {-Does feedback have an } \\
\text { influence on motivation for } \\
\text { learning? }\end{array}$ & & $\begin{array}{l}\text { The suggestion for improvement can be given in } \\
\text { different ways; there is no fixed format or example } \\
\text { of how it should be done. These different ways }\end{array}$ \\
\hline $\begin{array}{l}\text {-How is feedback given and } \\
\text { received? }\end{array}$ & & $\begin{array}{l}\text { are dependent on the prior knowledge of the } \\
\text { learners, age, motivation, gender, personal } \\
\text { interests, self-confidence, reading and writing } \\
\text { skills, and learning and interaction style..." }\end{array}$ \\
\hline
\end{tabular}

The research questions shown in the column headed "Initial object content", which presents material from the initial stages of the process, are reframed and elaborated in the column headed "Co-elaborated object." This latter column displays material from the co-elaborated object after the discussion illustrated in Excerpt 4. This example indicates the progress in the conceptual complexity of the group's shared knowledge object during this interaction. During the discussion, the concept of feedback is further specified and reframed as peer-feedback. The group discusses and defines this newly introduced concept using information from sources (line 10, Excerpt 4) regarding the specific context of their research (the VLC) and individual ideas. They create definitions and explanations that deepen the meaning of the concept, as shown in a more elaborated version in the third column.

Following the revision and elaboration of the research questions, as partly illustrated in Excerpt 5, the group moved on to the next step in further developing the research plan and design. The excerpt below shows an instance of interaction from the week following the elaboration of the research questions.

\section{Excerpt 6. Group D face-to-face discussion (7th project week)}

\footnotetext{
1. Alice:

“... Right, we are this far. Good job on the research questions.

2. Jane:

Yes, we ve gotten nicely on the way. [...] I looked up the information we needed, on peer-feedback.

2-idea uptake

3. Elly: Me too, found interesting stuff in the articles we collected. Useful leads by John (au. supervising teacher).
} 


\begin{tabular}{|c|c|c|}
\hline 4. Jane: & $\begin{array}{l}\text { Got some idea on how to proceed here... remember the } \\
\text { issue with feedback versus peer-feedback? }\end{array}$ & 1-identifying focus \\
\hline 5. Alice and Elly: & Yes. & \\
\hline 6. Jane: & $\begin{array}{l}\text { I think we contextualize it very clearly. Like, I would say } \\
\text { this is the type of environment, these are the features, } \\
\text { these are the activities envisioned, and feedback is part } \\
\text { of the learning design. }\end{array}$ & $\begin{array}{l}\text { 3-structuring ideas } \\
\text { 4-generating ideas }\end{array}$ \\
\hline 7. Alice: & Sort of... pedagogical design, you mean? & \\
\hline 8. Jane: & Yes, something like that. & \\
\hline 9. Alice: & $\begin{array}{l}\text { Then we can define feedback, using the literature, but } \\
\text { then explain that here we have peer-feedback at play, } \\
\text { and what the differences are. Like, what we started } \\
\text { writing on last time. }\end{array}$ & 4-co-elaborating ide \\
\hline 10. Elly: & $\begin{array}{l}\text { Yes. We can, actually, take each way of giving feedback, } \\
\text { like positive, negative, constructive, etc., and explain } \\
\text { how that works with peer feedback. }\end{array}$ & 4-generating ideas \\
\hline 11. Jane: & $\begin{array}{l}\text { Yes, but don't forget that our focus is on how peer-feedback } \\
\text { correlates with participation, motivation, and others... }\end{array}$ & 3-reframing focus \\
\hline 12. Elly: & $\begin{array}{l}\text { Yes, but that is the next step, right? First, we have to deal } \\
\text { with this feedback concept. }\end{array}$ & \\
\hline 13. Alice: & True, on the same page here." & \\
\hline
\end{tabular}

The excerpt starts with the group members acknowledging the work done on the research questions (line 1). Then, they start discussing the next step in their elaboration of the research plans, which is to operationalize the key concepts (line 2). They connect this discussion to points touched upon in the previous discussions (i.e., the distinction between the feedback and peer-feedback concepts, line 4). Group members indicate that they collected information on this matter (lines 2 and 3 ) and proceed to discuss strategies for elaboration. In line 6, Elly proposes an alternative, which is taken up and elaborated further by Alice in line 9. The group members take up ideas from the previous discussions (e.g., on the type of feedback) and generate new ideas to devise a way to pursue the elaborations (lines 9 and 10). Jane reminds the group about their research topic and focus, which should be kept in mind, but they all agree on the order of actions they have to pursue.

This excerpt illustrates how the group capitalizes on their previous discussions and understanding of concepts and used object drafts they had worked on as a starting point for their upcoming discussion. They explicitly acknowledge the point that they have reached in the process (research questions are now elaborated) and their achievement in this regard. They quickly strategize and continue their discussion on the next task that awaits them, the operationalization of concepts. The interaction is focused on content, and the group members very closely build on both previously constructed knowledge and each other's ideas. They seem to have a natural way of taking up and elaborating on each other's ideas generated during the discussion.

Overall, this group has devised a strategy for collaboration and work on the object, also illustrated partly in this excerpt. They first discussed concepts and strategies, created shared understanding when that was possible, and together wrote first drafts, looked up sources, and collected information, processed it in the elaboration of the drafts, and discussed the elaborated drafts in their following meetings. They worked in a targeted way, and their discussions were content-oriented. They used their discussions as a starting point for elaborating ideas in writing and rarely left the meetings without writing down the ideas and elaborations (in draft form) that emerged and gained shape during the meetings. Elaborations of the objects drafts pursued individually were always discussed in the group in the face-to-face meetings. 
Expression of shared epistemic agency

How shared epistemic agency is expressed is illustrated here using Group D's data, in implicit contrast with the collaboration of Group A. How this capacity manifested itself is not straightforward but intertwined in a subtle manner with the groups interaction and objectoriented work. The two excerpts below are selected from a face-to-face group discussion and the group interview at the end of the course period, respectively. Excerpt 7 displays a face-toface discussion episode in the preparation phase of the research, following a week after the elaborations and work on the research plan (showed in Excerpt 4 and 5). The discussion reflects the interaction at the point where the group encountered problems with regard to the operationalization of concepts and the mapping of the context for entrance points for the empirical investigation.

\section{Excerpt 7. Group D face-to-face discussion (9th project week)}

\begin{tabular}{|c|c|}
\hline 1. Jane: & $\begin{array}{l}\text { "... I've gone through our list of concepts and I think we are on track with the } \\
\text { operationalization. }\end{array}$ \\
\hline 2. Alice: & $\begin{array}{l}\text { Yes, beside that issue with which aspect in the VLC connects to which concept in our } \\
\text { framework... }\end{array}$ \\
\hline 3. Elly: & This thing really annoys me, cos we can $t$ move on. $[\ldots]$ \\
\hline 4. Jane: & $\begin{array}{l}\text { I think we are far enough now. The way I understand it is, we have defined peer- } \\
\text { feedback as (reading out loud definitions from the written texts). Then we listed the } \\
\text { key concepts (enumerates concepts) and now we have to operationalize and make } \\
\text { some connections. }\end{array}$ \\
\hline 5. Alice: & $\begin{array}{l}\text { Yes, for example, how does positive or negative peer-feedback have an influence on } \\
\text { presence or activities in VLC. My hypothesis is that the more negative the feedback, } \\
\text { the longer the presence. }\end{array}$ \\
\hline 6. Jane: & But where did you get that from? \\
\hline 7. Alice: & It's logical, isn't it? \\
\hline 8. Elly: & $\begin{array}{l}\text { You can't just invent something, it needs to be grounded. We had that in the methods } \\
\text { course. }\end{array}$ \\
\hline 9. Alice: & $\begin{array}{l}\text { Yes, but it's kind of common sense. Also, this issue with the client being a little vague, } \\
\text { we have to make it more concrete. }\end{array}$ \\
\hline 10. Elly: & $\begin{array}{l}\text { Could be... but we have to do it by the book. Like...ehm, we have our research } \\
\text { questions, based on literature, right? We use that to work out the hypotheses. Then we } \\
\text { have definitions of concepts, now we operationalize the concepts. }\end{array}$ \\
\hline 11. Jane: & $\begin{array}{l}\text { Wait... we should write down this one, as Alice formulated it, then we all go after } \\
\text { information in the articles we have. }\end{array}$ \\
\hline 12. Elly: & $\begin{array}{l}\text { Yes, smart! I think we can all write down the supporting or counter arguments, we } \\
\text { exchange and discuss them when we meet again. }\end{array}$ \\
\hline 13. Alice: & Ok, can be done. Shall we note down what we have for now and what we plan to do? \\
\hline 14. Jane: & Yes. (Retrieves the research plan document and starts typing)" \\
\hline
\end{tabular}

In this excerpt, the discussion revolves around a problem the group has struggled with for a while. They had identified the main theoretical concepts to work with, but the complexity of the virtual learning environment they were studying and the rather broad expectations from the client made this task difficult. In this episode, they are suggesting some possible hypotheses and alternatives for solving this problem (e.g., line 5). While approved as a strategy, the solution proposed by Alice is criticized by Elly (line 8), who explains some of the criteria and the rigor of the research methodology their study must comply with. It seems that they have a good theoretical knowledge of the empirical context, but they lack knowledge of how to bring 
them together into a coherent and sound research plan. They appear aware of this issue, and while they emphasize the need to meet these criteria, they start devising a strategy to address the problem. It resembles their usual collaborative strategy, but it is now spelled out explicitly, with the steps to be followed planned and written down.

This final excerpt is selected from the ending interview with Group D and focuses on the episodes of the interaction and work revolving around the problem that the group encountered regarding the operationalization and connection with the empirical context (presented also in Excerpt 6).

Excerpt 8. Ending interview, Group D

\begin{tabular}{|c|c|}
\hline Interviewer: & "...Do you remember the discussions regarding the operationalization of concepts? \\
\hline Alice: & $\begin{array}{l}\text { Oh yes, that was a tough one. I mean, at that point in time. Because we had some other } \\
\text { moments like that, but we managed them. }\end{array}$ \\
\hline Elly: & $\begin{array}{l}\text { That one was one of the moments when we felt that we don't understand what we are } \\
\text { doing, that we don't have the knowledge and skill needed to tackle this. }\end{array}$ \\
\hline Interviewer: & And how did you manage it? \\
\hline Alice: & $\begin{array}{l}\text { We were a little confused, at the beginning. We didn't know how to make the } \\
\text { connections, conceptual and, ehm... methodological... }\end{array}$ \\
\hline Jane: & $\begin{array}{l}\text { But then we discussed the problem, and figured some point where where we } \\
\text { could start. And what we would need to do. }\end{array}$ \\
\hline Alice: & $\begin{array}{l}\text { Yes, we first looked up some more information in articles, then exchanged materials, } \\
\text { then we met and talked again. We wrote up a first version, like first operationalization } \\
\text { and ideas, and Elly refined that at home. }\end{array}$ \\
\hline Elly: & $\begin{array}{l}\text { We asked for a supervision session and we asked John to take a look. We wanted to be } \\
\text { sure we didn't go totally the wrong way. }\end{array}$ \\
\hline Alice: & $\begin{array}{l}\text { Yes, and it was ok-ish, the way we started. After that we finished up that section and } \\
\text { could start working on the instruments. }\end{array}$ \\
\hline Elly: & I found it difficult and frustrating, but I think we learned a lot. \\
\hline Jane: & Yes, we surely had a break through there, got a better idea of how research works..." \\
\hline
\end{tabular}

This interview section was aimed at understanding how students experienced the operationalization of the problem previously discussed. As becomes evident, they were very aware of the problem and assigned importance to solving it thoroughly. They indicate that lack of knowledge and experience in conducting research has caused them confusion and frustration, but their explanation of their strategy also shows that they have approached the situation in a very rational and thorough fashion. They identified their shortcomings with regard to research and outlined their strategy for tackling the problem. While they clearly were at an impasse, as they indicate themselves, they did not consider giving up or relying on the supervising teacher and other authoritative instances. They devised a procedural strategy and a first draft of what they thought it should contain, which indicates their decisiveness and engagement in pursuing the task. Only after developing this outline did they ask for confirmation of their strategy and co-constructed content from the teacher.

How the group approached this problem and engaged in addressing it allows us to depict how shared epistemic agency is expressed in the context of interaction. This group expressed its agency through deliberate choices for gaining a good understanding of the problem, analyzing possible alternatives, searching for additional knowledge, and constructing knowledge that could represent a solution to this problem. In-depth discussion, the use of theorybased arguments, and concrete actions aimed at concrete knowledge solutions illustrate the 
epistemic aspects of agency. Envisioning a strategy to address the problem jointly, i.e., preparing alternative solutions and informing each other, continuously discussing the alternatives, and finally, co-elaborating the final version, illustrates the shared aspect of agency.

\section{Integration of findings}

The first two research questions asked were as follows: What are the characteristics of productive interactions in the context of group object-oriented collaboration? and How are productive interactions and knowledge object development interconnected? Productive interactions emerged in different ways and to varying extent in the five groups' activities. As shown in the overview of coded interactions, three interaction patterns emerged from the data. First, Group B's collaboration was dominated by interaction at the regulative level, with actions focusing more on procedural aspects of the collaboration and characterized by the frequent division of labor. This group finalized their project and passed the evaluation, which indicates that their interaction functioned from a process management viewpoint. The question that emerged is whether this interaction can be considered productive from an epistemic viewpoint and whether this group interacted sufficiently at this level to arrive at co-constructed knowledge. The interaction was more individual-based and process regulation-oriented. The assessment outcomes indicate that the conceptual elaboration and complexity of their research report was rather low. Second, the interaction of Group A's interaction appeared to be characterized by much discursive interaction, which resulted in an awareness of lack of knowledge, sharing knowledge from sources, and creating a shared understanding of ideas, knowledge, or identified problems that occurred during the work on the research plan. As shown in the analysis of Group A's excerpts, this led to the group reaching a common understanding of knowledge, negotiating explanations and definitions for concepts, and (re)framing ideas and problems. In various situations, creating a shared understanding of concepts (Group A) appeared crucial for the groups to move their work forward. This interaction was intensive and knowledge-laden, with the group's conversation being dominated by epistemic orientation and fewer regulative actions compared to Group B. It can be characterized as a productive but rather discourse-based interaction. Finally, as displayed by Group D, interactions involving generative collaborative actions, resulting in knowledge co-construction, were identified. These comprised discursive actions that led to shared understanding and knowledge, but also generating of new ideas, collaborative idea uptake, co-elaboration, and the materialization of ideas into object versions. Group D's data shows that this groups' interaction was not limited to discussions of ideas and concepts but also involved group members bringing in new ideas, with supporting material, elaborating and co-elaborating on these ideas and alternatives for further actions, and strategizing on co-construction of the knowledge object, its quality, and the related processes. These types of interactions were more object-oriented and illustrative of productive interaction. Figure 2 below graphically represents these last two patterns of interaction, as illustrated by the collaboration of groups A and D.

Group A's interaction trajectory shows a tendency toward discursive interaction, mainly aimed, as described above, at a shared understanding of knowledge. While this interaction was productive, the materialization of concepts and ideas into drafts to support them in being carried across sessions and enhancing joint elaborations, was less frequent. The interaction was more verbal, fewer draft objects were developed, and the object drafts appeared not to play an important role in the interaction. The knowledge content elaborated in the object was shared among the participants to a much lesser degree. For Group D, regularly discursive interaction (face-to-face meetings and online conversations) was the basis for the joint object construction. Concepts, ideas, and strategies were discussed in the group, textual versions were discussed 


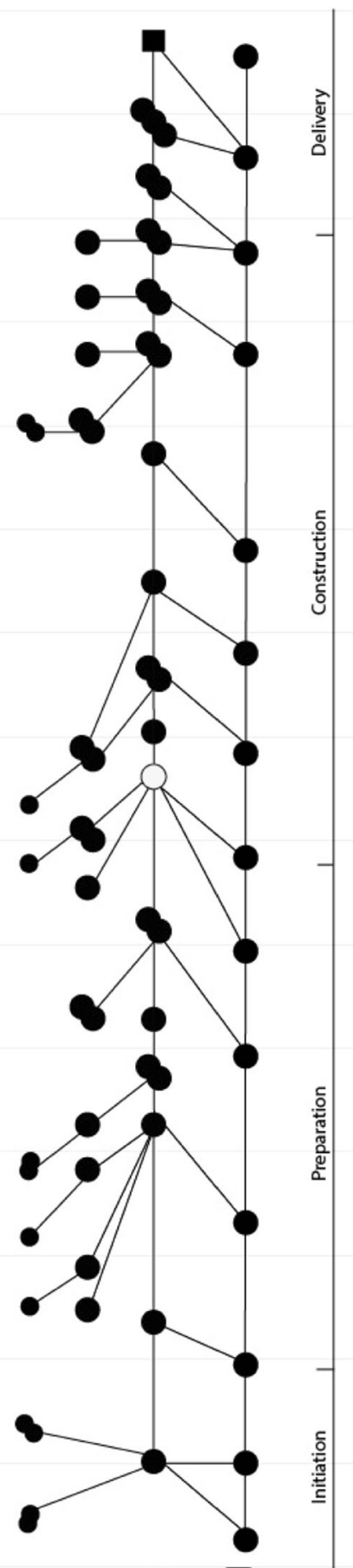

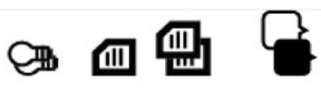
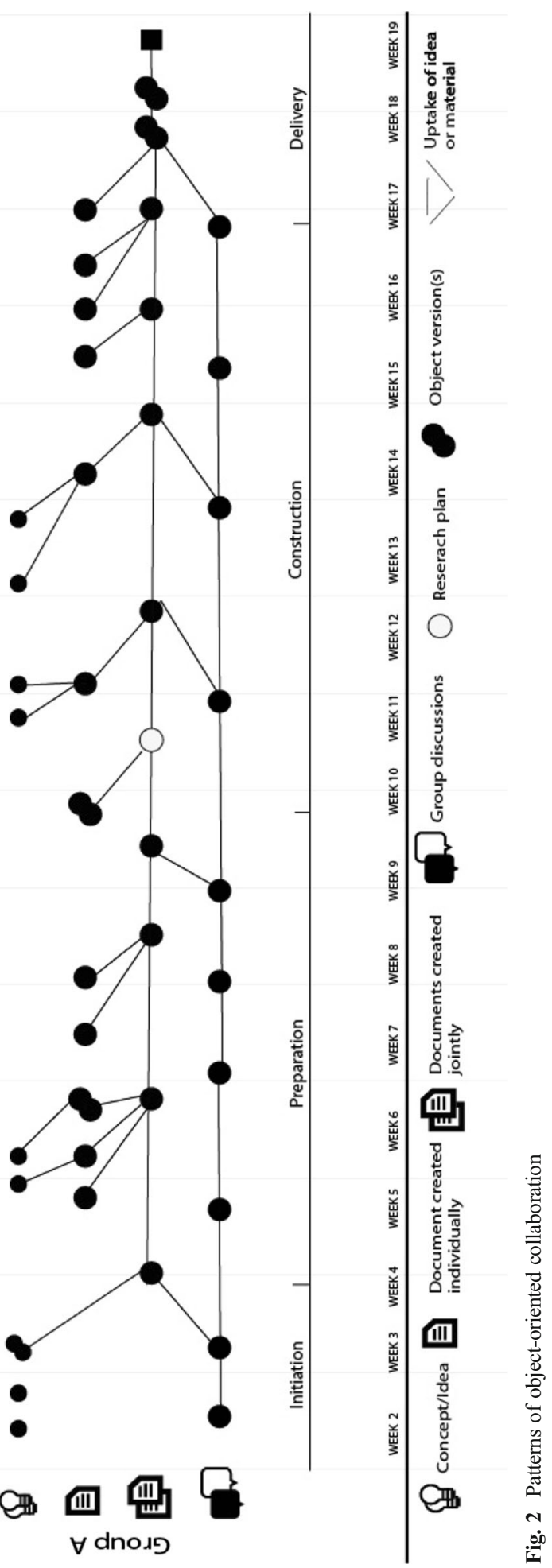
and amended, and co-elaboration occurred. Figure 2 shows that the number of draft versions of the text was notably higher than in Group A and that the majority of these drafts emerged and were elaborated upon following discursive interactions in the group meetings. This shows a better and more sustained integration of conversational interaction with the concrete coconstruction and co-elaboration of the object. It is a shared approach in which productiveness was expressed at both the discursive and the object-development levels. In addition, the type and frequency of interactions indicating the co-construction of knowledge objects are reflected in the quality of the knowledge objects developed by the groups.

The final research question asked, How is shared epistemic agency expressed and related to the groups object-oriented collaboration? The emergence and expression of shared epistemic agency in the context of collaborative research projects was illustrated in the collaboration of Group D. This group displayed a high awareness of the problem, engaged in sustained discussion to clarify where the problem originated and thought together about possible strategies to solve it, and organized joint work to apply these strategies. This sustained engagement in collaboration and the pursuit of suitable solutions for developing the knowledge object is a reflection of how the group achieved shared agency, in both epistemic and regulative terms. In addition, it supported an interaction that proved productive for the group in that they devised, constructed, and elaborated their shared ideas toward a complex and (from a methodological perspective) correct solution. The analyzed instance showed how individual members worked together in a joint effort to clarify both conceptual and procedural issues. The expression of agency here is characterized by individual input being weaved in together with this joint effort, which involves negotiation and supports a wider range of concepts or resources being deployed for the work on the (shared) object than it would in the case of individual action.

\section{Discussion}

This study aimed to gain an insight into the nature of productive interaction during objectoriented collaboration, and how both elements contribute to the development of knowledge objects. It also examined the way shared epistemic agency is expressed in this process. The study's main contribution is the empirical substantiation it provides to illustrate the different layers of object-oriented collaboration and their interconnection. The study is built on the assumption that developing knowledge objects in a process of collaboration requires some form of productive interaction, and that shared epistemic agency can fuel and steer this interaction. Using sociocultural perspectives as the main theoretical framework allowed the depiction of the productive aspects of collaboration, which translate to the need of human beings to express themselves by producing ideas and knowledge in interaction with others. From this perspective, productive interactions are conceived as communicative encounters between collaborating individuals, which lead to a shared understanding of concepts and ideas, the co-elaboration of the ideas into knowledge objects, and the sustained advancement of those knowledge objects.

This study provides an empirical contribution to the elaborations of the notion of productive interactions. It builds on and attempts to extend, among others, Baker's (1999) concept of constructive interactions and Mercer's (2002) view of exploratory talk, which highlight critical but constructive engagement with one another's ideas. However, while Baker considers that knowledge (re)construction is equal to negotiation, the current study takes Baker s elaboration one step further by proposing and illustrating a series of actions that make an interactional encounter ultimately productive, and in a more tangible manner. The interactions identified are considered productive in the sense that first, they create the grounds for co-elaboration and coconstruction of new knowledge objects; second, the interactions in the category of generative 
actions do in fact lead to the emergence of new knowledge and to the visible progress of the knowledge objects. The different types of action that make up these productive interactions and their occurrence are, nevertheless, interwoven. In the case of the two groups examined in depth, the analyses show how Group A achieved shared understanding through the verbal interaction of group members; at this level, such interaction can be considered productive. But the group did not achieve a deeper level of joint idea elaboration or materialization of their conversational accomplishment in the object drafts in the same way that Group D did. The latter succeeded in finding a balance between discussing concepts, ideas, and strategies, and materializing those into object sections, drafts, and versions through a joint approach. Ideally, this is the type of interaction that collaborative work should elicit and facilitate, and it has the dual potential to trigger mutual interdependency at epistemic level and to lead to a concretization of this accomplishment into tangible knowledge products.

Next, while the findings of the current study could be interpreted as being in line with the ideas and findings on interaction in discursive activities (argumentation, small group collaboration, or exploratory talk), they also reveal a less explored side of collaborative processes; this attempts, namely, to establish and illustrate the role of the developing knowledge objects in the interaction and the link between these two layers of the process. This aspect of the findings relates to Baker's conception of a shared goal in the constructive process, but it is more more concrete and material than a goal; also, to Barron's (2003) analysis of interaction in a relational space. But unlike Barron's study, which places a strong emphasis on the productivity of interactions within the relational space but makes no link to generating a knowledge solution, the interactions identified here are visible in the way the knowledge object evolves. Interestingly, Baker (1999) and Barron (2003) come very close to the idea of knowledge objects in the sense of conceptual artifacts (Bereiter 2002), but neither of the two studies pursues this idea in depth. The current study shows that a knowledge object is concrete, i.e., it materializes the knowledge collected or produced by the group (Paavola and Hakkarainen 2005) and has a more distinct value as the mediator of group interaction (Wertsch 1991). The relevance of the knowledge object for the convergence of the interaction becomes evident in this context, since it triggers group members to explain their point of view, confusion, and misunderstandings, but also their ideas, suggestions for action, and further elaborations of the object, as was the case in Group D's collaboration. Furthermore, the findings also illustrate a two-way relationship between the knowledge object and the interactional process. The knowledge object's structure and elaboration are determined by the interactions, especially those of an epistemic nature, and this was evidenced in Group D's interaction. At the same time, the way the knowledge object develops influences the content and the direction of the interaction. In this context, Group D also experienced that their interaction was strongly influenced by the way their shared object developed, and by their confusion and lack of insight into how elaborations should be pursued.

Another contribution of this study concerns the emergence and expression of shared epistemic agency. Data that shed light on how discussion among group members triggers problems, but also a shared effort to find solutions, illustrates a knowledge object's potential to elicit more convergent, complex interaction at the epistemic level. Here, the notion of shared epistemic agency proves useful for explaining what drove the groups to engage in particular types of interaction and go about working on the knowledge object. This type of deliberate, goal-oriented approach characterized by a high level of awareness and engagement, as identified in Group D's collaborative work, is rather generic and is in line with other findings on agency (Charles and Shumar 2009; Damşa et al. 2010; Schwartz and Okita 2004). In addition, such action bears a close resemblance to what Engle and Conant (2002) labeled as disciplinary engagement performed in relation to a specific task within a particular discipline. However, the current study contributes to a better understanding of how agentic action of this nature impacts 
interaction involving the construction of knowledge and the way shared knowledge objects are co-developed. These findings feed into the discussion on the complexity of the agency construct, highlighting two main aspects. The first concerns the epistemic nature of agency in this context, with the results showing that it can be triggered and fueled by concrete objects that materialize group production and form a basis for devising further solutions. This highlights the importance of the productive aspect of agency, as emphasized by Schwartz and Okita (2004), which is manifested here in Group D's sustained pursuit of ideas and solutions; an approach that required them to go beyond the usual problem-solving tasks and the outlining of research strategies. The second aspect refers to the intersubjectivity that makes shared agency possible. From this perspective, the expression of agency shown in these findings is characterized by the weaving together of individual input and joint efforts, which involves negotiation and supports the deployment of a wider range of concepts or resources for work on the (shared) object than would be the case for individual action. While this group displayed the capacity to address atypical situations and problems, the question arising in relation to those findings is whether all collaborative groups have and can express such shared epistemic agency.

\section{Multi-layeredness and temporality}

Most importantly, one of the most compelling assumptions in this study is the multi-layered nature of learning, conceived as knowledge co-construction. As indicated at the start of the article, this multi-layeredness can be viewed from a structural and from an analytic perspective, since all these aspects are closely related. The structural aspect has been discussed in depth in various interaction studies (see mainly Stahl 2009a) and it raises the issue of whether collaborative learning relies on interaction as a way of simply combining individual cognitions, and the implications that has for the unit of analysis. The analytic aspect, which this study attempted to investigate in particular, comprises the layers that are assembled in the co-construction process, namely, interactions, knowledge objects, and agency. In the context of the current study, the structural aspects relate to the notion of intersubjectivity (Matusov 2001) and the manner in which interaction around a shared object can bring together the engagement and contributions of individuals, intertwined in a joint effort. As shown in the analyses, there is dynamism in the relationship between intersubjectivity and how it is enacted - that is, how individual group members arrive at joint thinking, strategizing, and action - and the embodiment of the knowledge into objects. Furthermore, the characteristics of the interaction and the way it takes place are, in an ingrained manner, connected to the knowledge objects that emerge from and are developed through the interaction; this relates to the aspect of multi-layeredness previously mentioned. The students' interaction examined here focuses not just on the shared understanding of knowledge, but also on the translation of this knowledge into tangible objects, which are advanced iteratively.

In this regard, one distinctive contribution of the empirical examination is its attempt to follow, along with the unfolding interaction, the knowledge that emerges and gains shape through the interaction. This analysis focuses on the trajectory of the knowledge from the moment it enters the interaction process (e.g., ideas and concepts) until it has materialized and is elaborated into the final objects produced by the groups. Few studies have traced knowledge in this way, and those that attempted to do so (Furbeg and Ludvigsen, 2008, Krange 2007; Sarmiento-Klapper, 2009) focused on the concepts' trajectories and did not examine their further elaboration. The results of the present study add to this body of research by showing how ideas and concepts identified as "important" are put forward in the group. The knowledge in its preliminary form was dealt with in different ways using an array of alternatives, some of which are displayed in the interaction patterns represented in Fig. 2. The results of the study add to the 
relevant body of knowledge by disclosing what happens to the knowledge once shared discourse within the group is achieved, at the point when those verbal elaborations have to be "frozen", and then become materialized. This examination was taken further by connecting it to the ways in which emergent knowledge is elaborated. The manner in which the groups shaped knowledge and engaged with it for a period of time was, in a sense, also representative of how they positioned themselves when addressing the open-ended problems that triggered their collaborative work. The interconnection between interaction and the emerging objects is one of the main aspects of intellectual interdependency (Valsiner 1994) that makes productive collaboration possible. The objects created by the groups passed through those different functions, while shaping the ongoing interaction. To conclude, a multi-layered analysis provides the opportunity to address the interconnection between the various aspects of the co-construction process in a more diligent manner than is possible in the case of studies analyzing those layers independently.

Finally, the analysis of interaction and object development from a trajectory perspective allows the mutuality of this relationship to be unveiled and understood and the unfolding of the process to be made visible. The current results elaborate on the dialogical studies of interaction by showing groups engaging in trajectories that go beyond mere discursive interaction, and go on to build on shared elaborations, and follow up on iterations. In this research, one way in which the productivity of the interaction manifests is through the sequence of actions in the interaction that leads to the co-elaboration of the knowledge objects. Given the complexity and length of the projects, organizing and attending to a sequential structure in which knowledge is not only generated and discussed but also taken and followed up, elaborated upon, and refined is of essential importance. The current findings suggest that materializing knowledge, whether in a preliminary or advanced form of elaboration, into situational objects (Jahreie 2010) serves to preserve the continuity of the process. It also aids the progressive accumulation of conceptualizations and elaborations (Muukkonen and Lakkala, 2009) and contributes to the co-construction process by freezing the generated knowledge at particular moments during the process. As stated earlier, the knowledge object drafts played a catalyzing role in the groups' interactions, and that was also expressed in how the course of the interaction changed or adjusted with time, in order ultimately to become meaningful for the co-construction of the objects.

\section{Implications for research and practice}

From an educational-practice perspective, the idea that collaboration requires explicit orchestration finds resonance in this study's findings. Specific organization and instruction appear necessary for group-based work to be productive, and studies such as the one presented here provide input in relation to the design of such supporting structures. The main recommendation based on this study's finding concerns the important role of collaboration generating a shared, tangible outcome; in the case presented here, a knowledge object. Creating the conditions for students to discuss and elaborate on ideas, providing them with the space to explore, and encouraging an investigative attitude are important features of a design aimed at supporting productive interaction. In addition, the task should be formulated in such a manner that it requires students to capitalize on this interaction, and to materialize their discussions, ideas, contributions into objects that are dynamic in their development and emergence from the interaction. In turn, this type of collaboration might require specific type of guidance. This study hints that, from an instructional perspective, such interaction can be designed and supported by adjusting the nature and complexity of tasks, by tailoring the guidance for each groups needs, and by considering the aspects analyzed in this study such as interaction, object development, and shared epistemic agency when assessing the learning activity. As an important note, the emerging technologies designed for collaboration have considerable 
potential to provide support for this part of the process that leads to knowledge coconstruction. When designed in a targeted manner, such technologies should involve the type of tools and functionalities that support joint work on knowledge content, and allow following up and tracing the co-constructed knowledge in a consistent manner. From a research perspective, such technology can also allow the retrieval of the material produced, and make analyses of its detailed evolution in time feasible.

Lastly, this study highlights a number of aspects that require further investigation and discussion. First, it provides a rather succinct insight into knowledge objects and of their development over time, but it does not comprise a comprehensive analysis of the process and developing objects. Additionally, in-depth investigations are needed to pinpoint object-mediated collaboration in terms of the nature of the knowledge objects and their semantic content, and how those objects affect learners' actions. Second, a methodological challenge lies ahead with regard to developing methods and instruments that allow a comprehensive multi-layered analysis of the knowledge objects created, and of group elaboration strategies. The findings in this study show how learning takes place on different planes and over time, and is fueled by various resources, with researchers assigned the difficult task of unveiling the mechanisms of this complex phenomenon. Finally, this study also points up the importance of investigating pedagogical designs and technology to support productive interactions and collaborative object development. Such investigations should highlight ways to create improved pedagogical designs and technology that support students in their collaborative work, as well as ways to evaluate this type of learning by taking into account both the interactional process and its (emerging) outcomes.

\section{Conclusion}

This study attempted to step beyond merely analyzing interaction in collaborative learning; it also considered the interconnection of those interactions in terms of how they are mediated and intertwined with shared epistemic agency, and how they lead to the co-construction of knowledge objects. As a result, it contributes to the field by providing a view of the phenomenon that emphasizes its multiple layers and which, through its complexity, requires a versatile investigation approach.

In closing, the study and its findings do not serve merely to underscore the nature and relevance of understanding how collaboration can be a natural part of learning, but also highlight the need to shift towards a view of collaboration that acknowledges and emphasizes the value of productive interaction in the context of knowledge-driven, technology-supported learning contexts. While the elements, the mechanisms and the layers in this process emerge as highly intricate and complex, in-depth understanding can contribute to shaping the learning process in its emergence and can also support students in their quest to be more than mere course-takers, but also producers of knowledge.

Acknowledgments This study was carried out as part of the KP-Lab project (Knowledge Practices Laboratory, www.kp-lab.org), funded by the European Community under the Information Societies Technology 6th Framework Programme.

I am grateful to Professor Sten Ludvigsen for the constructive feedback on the manuscript. I thank Jerry Andriessen for making this study possible, my colleagues at InterMedia for valuable comments and the participating students for the research opportunities enabled by their work.

Open Access This article is distributed under the terms of the Creative Commons Attribution License which permits any use, distribution, and reproduction in any medium, provided the original author(s) and the source are credited. 


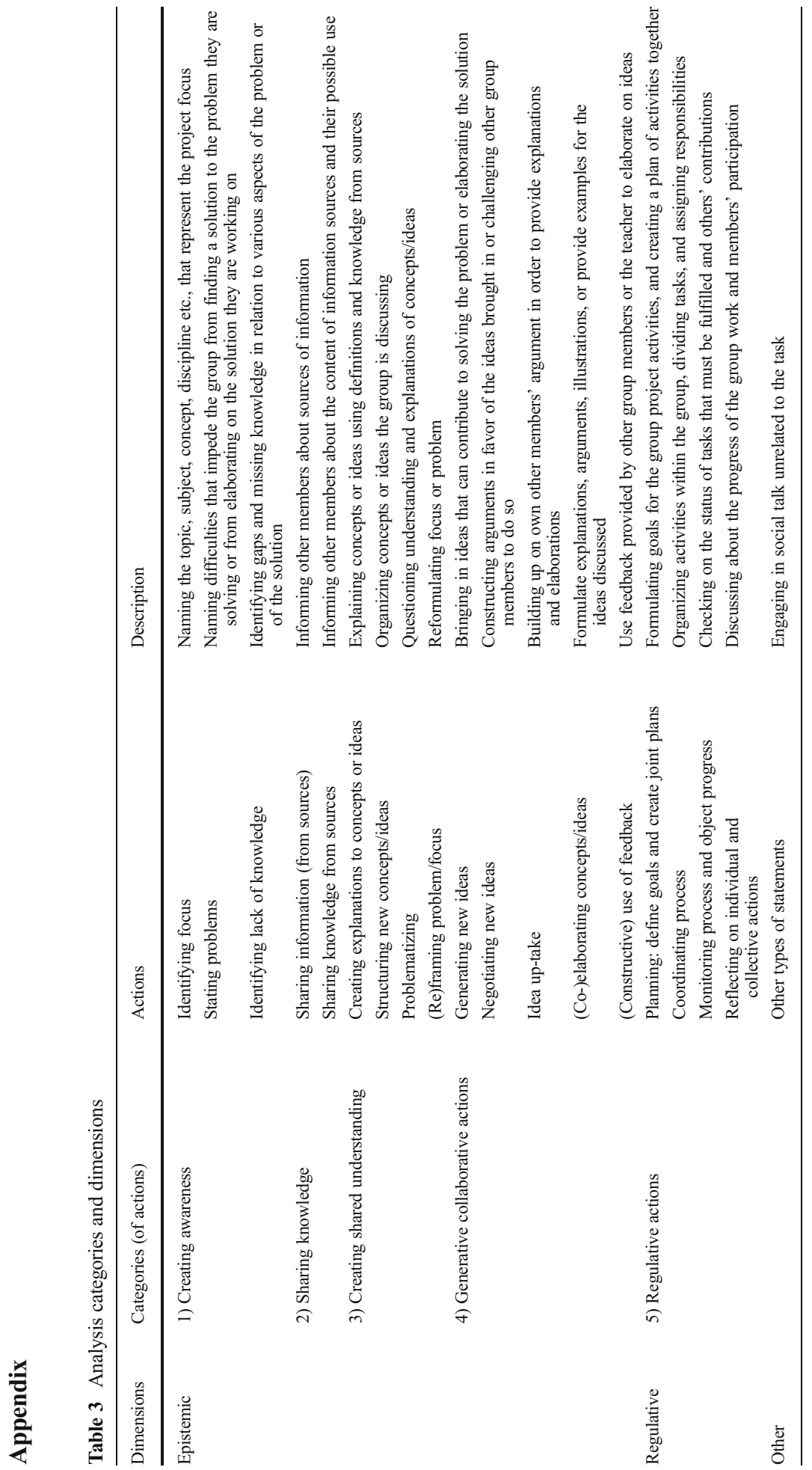




\section{References}

Ahuja, M., \& Galvin, J. (2003). Socialization in virtual groups. Journal of Management, 29, 161-185. doi:10. 1016/j.jm.2004.05.002.

Baker, M. J. (1999). Argumentation and constructive interaction. In P. Coirier \& J. Andriessen (Eds.), Foundations of argumentative text processing (pp. 179-202). Amsterdam: University of Amsterdam Press.

Barron, B. (2003). When smart groups fail. Journal of the Learning Sciences, 12, 307-359. doi:10.1207/ S15327809JLS1203 1.

Bereiter, C. (2002). Education and mind in the knowledge age. Hillsdale: Lawrence Erlbaum Associates.

Bowen, G. A. (2009). Document analysis as a qualitative research method. Qualitative Research Journal, 9(2), $27-40$.

Carlile, P. R. (2002). A pragmatic view of knowledge and boundaries: Boundary objects in new product development. Organization Science, 13(4), 442-455. doi:10.1287/orsc.13.4.442.2953.

Çakir, M. P., Zemel, A., \& Stahl, G. (2009). The joint organization of interaction within a multimodal CSCL medium. International Journal of Computer-Supported Collaborative Learning., 4(2), 115-149. doi:10. 1007/s11412-009-9061-0.

Charles, E. S. \& Shumar, W. (2009). Student and team agency in VMT. In G. Stahl, (Ed.) Studying virtual math teams (pp. 207-224). Computer-supported Collaborative Learning Series, Vol 11. New York: Springer

Collins, A., Joseph, D., \& Bielaczyc, K. (2004). Design research: Theoretical and methodological issues. Journal of the Learning Sciences, 13, 15-42. doi:10.1207/s15327809j1s1301_2.

Cress, U., Held, C., \& Kimmerle, J. (2013). The collective knowledge of social tags: Direct and indirect influences on navigation, learning, and information processing. Computers \& Education, 60(1), 59-73. doi:10.1016/j.compedu.2012.06.015.

Creswell, R. W. (2007). Qualitative inquiry and research design (2nd ed.). London, England: Sage.

Damşa, C. I., Kirschner, P. A., Andriessen, J. E. B., Erkens, G., \& Sins, P. H. M. (2010). Shared epistemic agency: An empirical study of an emergent concept. Journal of the Learning Sciences, 19, 143-186. doi:10. 1080/10508401003708381.

Damșa, C., Ludvigsen, S., \& Andriessen, J. (2013). Knowledge co-construction-Epistemic consensus or relational assent? In M. Baker, J. Andriessen, \& S. Jaarvela (Eds.), Affective learning together: Social and emotional dimensions of collaborative learning (pp. 97-119). London: Routledge. New perspectives in learning and instruction series.

Emirbayer, M., \& Mische, A. (1998). What is agency? American Journal of Sociology, 103, 962-1023.

Engle, R. A., \& Conant, F. C. (2002). Guiding principles for fostering productive disciplinary engagement: Explaining an emergent argument in a community of learners classroom. Cognition and Instruction, 20(4), 399-483.

Engle, R. A., \& Faux, R. B. (2006). Towards productive disciplinary engagement of prospective teachers in educational psychology: Comparing two methods of case-based instruction. Teaching Educational Psychology, 1(2), 1-22.

Engeström, Y., \& Sannino, A. (2010). Studies of expansive learning: Foundation, findings and future challenge. Educational Research Review, 5, 1-24. doi:10.1016/j.edurev.2009.12.002.

Fuks, H., \& Pimentel, M. (2009). Studying response-structure confusion in VMT. In G. Stahl (Ed.), Studying virtual math teams (pp. 373-397). Computer-supported Collaborative Learning Series, Vol 11. New York: Springer

Furberg, A., \& Ludvigsen, S. R. (2008). Students' meaning-making of socio-scientific issues in computermediated settings: Exploring learning through interaction trajectories. International Journal of Science Education, 30, 1775-1799. doi:10.1080/09500690701543617.

Goodyear, P., \& Zenios, M. (2007). Discussion, collaborative knowledge work and epistemic fluency. British Journal of Educational Studies, 55(4), 351-368. doi:10.1111/j.1467-8527.2007.00383.x.

Hmelo-Silver, C. (2004). Problem-based learning: What and how do students learn? Educational Psychology Review, 16(3), 235-266. doi:10.1023/B:EDPR.0000034022.16470.f3.

Hmelo-Silver, C., Chinn, C., Chan, C., \& Donell, A. (2013). The international handbook of collaborative learning. NY: Routledge.

Jahreie, C. F. (2010). Making sense of conceptual tools in student-generated cases: Students teachers problemsolving. Teaching and Teacher Education, 26(6), 1229-1237. doi:10.1016/j.tate.2009.12.002.

Janssen, J., Erkens, G., Kirschner, P. A., \& Kanselaar, G. (2010). Effects of representational guidance during computer-supported collaborative learning. Instructional Science, 38, 59-88.

Jordan, B., \& Henderson, A. (1995). Interaction Analysis: Foundations and Practice. Journal of the Learning Sciences, 4, 39-103. doi:10.1207/s15327809j1s0401_2. 
Kaptelinin, V. (2005). The object of activity: Making sense of the sense-maker. Mind, Culture and Activity, 12(1), 4-18. doi:10.1207/s15327884mca1201 2.

Knorr-Cetina, K. (1997). Sociality with objects: Social relations in postsocial knowledge societies. Theory Culture \& Society, 14(4), 1-30. doi:10.1177/026327697014004001.

Knorr-Cetina, K. (2001). Objectual practice. In T. R. Schatzki, K. Knorr-Cetina, \& E. von Savigny (Eds.), The practice turn in contemporary theory (pp. 175-188). London: Routledge.

Krange, I. (2007). Students' conceptual practices in science education-Productive disciplinary interactions in a participation trajectory. Cultural Studies of Science Education, 2, 171-203. doi:10.1007/s11422-006-9040-y.

Lee, E., Chan, C. K. K., \& van Aalst, J. (2006). Students assessing their own collaborative knowledge building. International Journal of Computer-Supported Collaborative Learning, 1, 277-307. doi:10.1007/s11412006-6844-4.

Leont'ev, A. N. (1978). Activity, consciousness, personality. Englewood Cliffs: Prentice Hall.

Lindwall, O., \& Lymer, G. (2011). Uses of "understand" in science education. Journal of Pragmatics, 43(2), 452-474.

Linell, P. (2009). Rethinking language, mind and world dialogically: Interactional and contextual theories of human sense-making. Advances in cultural psychology: constructing human development series. Charlotte: Information Age Publishing Inc.

Ludvigsen, S. (2010). Sociogenesis and cognition. The struggle between social and cognitive activities. In B. Schwarz, T. Dreyfus, \& R. Hershkowitz (Eds.), Transformation of knowledge through classroom interaction (pp. 302-318)). New York: Routledge.

Ludvigsen, S. \& Mørch, A. (2010). Computer-Supported Collaborative Learning: Basic Concepts, Multiple Perspectives, and Emerging Trends. In E. Baker, P. Peterson, \& B. McGaw, International Encyclopedia of Education (Eds.), 3rd ed., Elsevier.

Matusov, E. (2001). Intersubjectivity without agreement. Mind, Culture, and. Activity, 3(1), 25-45.

Medina, R., Suthers, D. D., \& Vatrapu, R. (2009). Representational practices in VMT. In G. Stahl (Ed.), Studying virtual math teams (pp. 185-205),). Computer-supported Collaborative Learning Series, Vol 11. New York: Springer

Mercer, N. (2000). Words and Minds: how we use language to think together. London: Routledge.

Mercer, N. (2002). Developing dialogues. In G. Wells \& G. Claxton (Eds.), Learning for life in the 21st century: Sociocultural perspectives on the future of education (pp. 141-153). Oxford: Blackwell.

Mercer, N., \& Wegerif, R. (1999). Is "exploratory talk" productive talk? In K. Littleton \& P. Light (Eds.), Learning with Computers: Analysing productive interaction (pp. 79-101). London: Routledge.

Miettinen, R., \& Virkkunen, J. (2005). Epistemic objects, artefacts and organizational change. Organization, 12, 437-456. doi: $10.1177 / 1350508405051279$.

Miyake, N. (1986). Constructive interaction and the iterative process of understanding. Cognitive Science, 10(2), $151-177$

Muukkonen, H., \& Lakkala, M. (2009). Exploring metaskills of knowledge-creating inquiry in higher education. International Journal of Computer-Supported Collaborative Learning, 4(2), 187-211.

Nicolini, D., Mengis, J., \& Swan, J. (2012). Understanding the role of objects in multidisciplinary collaboration. Organization Science, 23, 612-629.

Paavola, S., \& Hakkarainen, K. (2005). The knowledge creation metaphor-an emergent epistemological approach to learning. Science \& Education, 14, 535-557. doi:10.1007/s11191-004-5157-0.

Palonen, T., \& Hakkarainen, K. (2000). Patterns of interaction in computer-supported learning: A social network analysis. In B. Fishman \& S. O'Connor-Divelbiss (Eds.), 4th International Conference of the Learning Sciences (pp. 334-339). Mahwah, NJ: Erlbaum.

Ramduny-Ellis, D., Dix, A., Rayson, P., Onditi, V., Sommerville, I., \& Ransom, J. (2005). Artefacts as designed, artefacts as used: Resources for uncovering activity dynamics. Cognition, Technology, and Work, 7, 76-87. doi:10.1007/s10111-005-0179-1.

Remesal, A. \& Colomina, R. 2013 Social presence in online small collaborative group work: a socioconstructivist account. Computers \& Education 60, 357-367. doi: S0360131512001698

Rheinberger, H.-J. (1997). Towards history of epistemic things: Synthesizing proteins in the test tube. Stanford: Stanford University Press.

Roschelle, J. (1992). Learning by collaborating: Convergent conceptual change. Journal of the Learning Sciences, 2, 235-276. doi:10.1207/s15327809jls0203_1.

Rummel, N. \& Spada. (2005). Learning to collaborate: An instructional approach to promoting collaborative problem solving in computer-mediated settings, Journal of the Learning Sciences, 14(2), 201-241. doi: $10.1207 / \mathrm{s} 15327809 \mathrm{jl} 1 \mathrm{l} 1402 \_2$

Sarmiento-Klapper, J. W. (2009). The sequential co-construction of the joint problem space. In G. Stahl \& Studying virtual math team (Eds.), Computer-supported collaborative learning series (pp. 83-98)). New York: Springer. 
Sawyer, R. K., \& Berson, S. (2004). Study group discourse: How external representations affect collaborative conversation. Linguistics and Education, 15, 387-412.

Scardamalia, M. (2002). Collective cognitive responsibility for the advancement of knowledge. In B. Smith (Ed.), Liberal Education in a Knowledge Society (pp. 67-98). Chicago: Open Court.

Schwartz, D., and Okita, S. (2004). The productive agency in learning by teaching. Unpublished manuscript. Retrieved on March 18, 2012 from http://aaalab.stanford.edu/papers/ProductiveAgencyinLearningbyTeaching.pdf

Sfard, A., \& Kieran, C. (2001). Cognition as communication: Rethinking learning-by-talking through multi-faceted analysis of students' mathematical interactions. Mind, Culture, and Activity, 8(1), $42-76$.

Slof, B., Erkens, E., Kirschner, P. A., \& Helms-Lorenz, M. (2013). The effects of inspecting and constructing part-task-specific visualizations on team and individual learning. Computers and Education, 60, 221-233. doi:10.1016/j.compedu.2012.07.019.

Sins, P. H. M., Bauters, M., \& Damşa, C. I. (2008). Knowledge practices environment: Design and application of technology for trialogical learning. In P. Dillenbourg \& M. Specht (Eds.), Times of convergence: Technologies across learning contexts (pp. 419-430). Berlin, Germany: Springer Verlag.

Stahl, G. (2003). Meaning and interpretation in collaboration. In B. Wasson, S. Ludvigsen, \& U. Hoppe (Eds.), Designing for change in networked learning environments: Proceedings of the International Conference on Computer Support for Collaborative Learning (pp. 523-532). Bergen, Norway: Kluwer. Retrieved from http://GerryStahl.net/cscl/papers/ch20.pdf.

Stahl, G. (2009a). Studying virtual math teams. Computer-supported Collaborative Learning Series, Vol 11. New York: Springer. doi:10.10007/978-1-4419-0228-3

Stahl, G. (2009b). Towards a science of group cognition. In G. Stahl, (ed.), Studying virtual math teams (pp. 555580). Computer-supported Collaborative Learning Series, Vol 11. New York: Springer. doi:10.10007/978-14419-0228-3

Stahl, G. (2009c). Mathematical discourse as group cognition. In G. Stahl, (ed.), Studying virtual math teams (pp. 31-41). Computer-supported Collaborative Learning Series, Vol 11. New York: Springer. doi:10.10007/ 978-1-4419-0228-3

Stahl, G. (2013). Learning across levels. International Journal of Computer-Supported Collaborative Learning, 8(1), 1-12. doi:10.1007/s11412-013-9169-0.

Säljö, R. (2004). Learning and technologies, people and tools in co-ordinated activities. International Journal of Educational Research, 41, 489-494. http://dx.doi.org/10.1016/j.ijer.2005.08.013

Teasley, S. D., \& Roschelle, J. (1993). Constructing a joint problem space: The computer as a tool for sharing knowledge. In S. P. Lajoie \& S. J. Derry (Eds.), Computers as cognitive tools (pp. 229-258). Hillsdale, NJ: Lawrence Erlbaum Associates, Inc.

Valsiner, J. (1994). Bidirectional cultural transmission and constructive sociogenesis. In W. de Graaf \& R. Maier (Eds.), Sociogenesis reexamined (pp. 47-70). New York: Springer.

Valsiner, J., \& van der Veer, R. (2000). The social mind: Construction of the idea. New York: Cambridge University Press.

van Aalst, J., \& Chan, C. K. K. (2007). Student-directed assessment of knowledge building using electronic portfolios in Knowledge Forum. Journal of the Learning Sciences, 16, 175-220. doi:10.1080/ 10508400701193697.

Vygotsky, L. S. (1978). Mind in society: the development of higher psychological processes. Cambridge: Harvard University Press.

Webster, L., \& Mertova, P. (2007). Using narrative inquiry as a research method: An introduction to using critical event narrative analysis in research on learning and teaching. New York: Routledge.

Weinberger, A., \& Fischer, F. (2006). A framework to analyze argumentative knowledge construction in computer-supported collaborative learning. Computers \& Education, 46, 71-95. doi:10.1016/j.compedu. 2005.04.003.

Wertsch, J. V. (1991). Voices of the mind: A sociocultural approach to mediated action. Cambridge, MA: Harvard University Press.

Wertsch, J. V. (1998). Mind As Action. NewYork: Oxford University Press.

Yin, R. (2003). Case study research: Design and methods (3rd ed.). Thousand Oaks, CA: Sage Publications. 